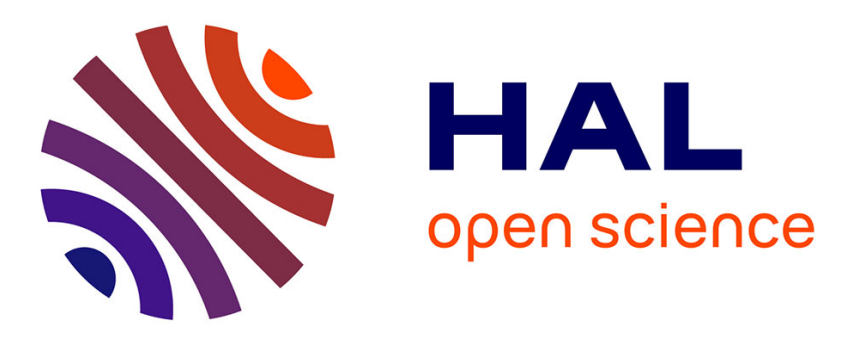

\title{
Thermal mixing in a T-junction: Novel CFD-grade measurements of the fluctuating temperature in the solid wall
}

Olivier Braillard, Richard Howard, Kristian Angele, Afaque Shams, Nicolas Edh

\section{To cite this version:}

Olivier Braillard, Richard Howard, Kristian Angele, Afaque Shams, Nicolas Edh. Thermal mixing in a T-junction: Novel CFD-grade measurements of the fluctuating temperature in the solid wall. Nuclear Engineering and Design, 2018, 330, pp.377-390. 10.1016/j.nucengdes.2018.02.020 . cea-02430130

\section{HAL Id: cea-02430130 https: / hal-cea.archives-ouvertes.fr/cea-02430130}

Submitted on 7 Jan 2020

HAL is a multi-disciplinary open access archive for the deposit and dissemination of scientific research documents, whether they are published or not. The documents may come from teaching and research institutions in France or abroad, or from public or private research centers.
L'archive ouverte pluridisciplinaire HAL, est destinée au dépôt et à la diffusion de documents scientifiques de niveau recherche, publiés ou non, émanant des établissements d'enseignement et de recherche français ou étrangers, des laboratoires publics ou privés. 


\title{
Thermal mixing in a T-junction: Novel CFD-grade measurements of the fluctuating temperature in the solid wall
}

\author{
Olivier Braillard ${ }^{\mathrm{a}}$, Richard Howard ${ }^{\mathrm{b}}$, Kristian Angele ${ }^{\mathrm{c}}$, Afaque Shams ${ }^{\mathrm{d}, *}$, Nicolas Edh $^{\mathrm{e}}$ \\ ${ }^{\text {a } C o m m i s s a r i a t ~ a ̀ ~ l ' E n e r g i e ~ A t o m i q u e ~ e t ~ a u x ~ E n e r g i e s ~ A l t e r n a t i v e s, ~ F r a n c e ~}$ \\ b Électricité de France R\&D, France \\ ${ }^{\mathrm{c}}$ Vattenfall $A B$, Sweden \\ ${ }^{\mathrm{d}}$ Nuclear Research and Consultancy Group, The Netherlands \\ e Forsmarks Kraftgrupp AB, Sweden
}

\section{A R T I C L E I N F O}

\section{Keywords:}

Thermal fatigue

T-junction

Experiments

Novel senor

Sharp corner

Round corner

\begin{abstract}
A B S T R A C T
This article reports new experiments performed with the purpose of generating novel data of the fluctuating temperature inside the solid in the mixing region between hot and cold water in a T-junction. This data has been measured using a novel sensor (coefh) developed at the Commissariat à l'Energie Atomique et aux Energies Alternatives (CEA) in Cadarache, France. These experiments are performed within the framework of the MOTHER project. The main objective of the MOTHER project is to validate various CFD approaches (such as LES, Hybrid i.e. RANS/LES and RANS) for transient heat transfer in a T-junction configuration including the pipe wall. Hence, the performed experiments have focused on accurately measuring and documenting the boundary conditions to be able to have a well-defined database for CFD validation. The tests are performed for two different Reynolds numbers 40000 and 60000 and for two different T-junction geometries; a sharp corner and a round corner.
\end{abstract}

\section{Introduction}

Thermal fatigue is a degradation mechanism which occurs in a wide range of industrial applications. One such application is the primary piping system of a nuclear power plant, where the mixing of flows with different temperature can lead to thermal fatigue. The consequences of thermal fatigue can be serious and can cause sufficient structural damage for a power plant to require a complete shut-down. Therefore, it is highly relevant in the context of aging and the life time management of a nuclear power plant. In the last decade, several efforts have been made for the assessment of thermal fatigue (Braillard et al., 2006; Chapuliot et al., 2005; Coste et al., 2008; Fontes et al., 2009; Kamide et al., 2009; Smith et al., 2013). The generic configuration that is mostly considered is the T-junction, where the mixing of two separate hot and cold streams occur immediately downstream of the T-junction. This transient turbulent mixing results in high temperature fluctuations next to and inside the pipe walls. The first step is, however, to be able to predict the temperature fluctuations in the fluid close to the wall. In this regard, an extensive amount of research work has been performed in relation to the application of CFD for the assessment of thermal fatigue in the T-junction (Gillis et al., 2013; Howard and Pasutto, 2009; Jayaraju et al., 2010; Kuhn et al., 2010; Nakamura et al., 2009; Westin

\section{et al., 2008).}

In the recent past, an attempt was made to evaluate the accuracy in the CFD predictions such thermal fluctuations in the form of the OECD CFD Benchmark for the Vattenfall T-junction configuration (Smith et al., 2013). The considered configuration was based on adiabatic walls. As an outcome of the benchmarking exercise, one of the recommendations was the need for more insights into the heat transfer phenomenon from the fluid flow to the wall. This recommendation was the main motivation behind the MOTHER project, with the purpose of generating novel data of the fluctuating temperature in the solid wall for the validation of CFD calculations.

The main objective of the MOTHER project (Modelling T-junction HEat TransfeR) is to validate various CFD approaches (such as LES, Hybrid (RANS/LES) and RANS) for transient heat transfer in a T-junction configuration including the wall with new experimental data. These CFD calculations have to take into account the effect of the wall and the heat transfer. The mean and fluctuating fields of the velocity and the temperature (fluid and wall) are also evaluated. The effects of the mixing tee geometry (a round and a sharp corner) as well as Reynolds numbers (Re) are investigated at $\mathrm{Re}=40000$ and $\mathrm{Re}=60000$. The FATHERINO facility at CEA in Cadarache is used as the test facility. This facility is specifically designed to study the

\footnotetext{
* Corresponding author.

E-mail address: shams@nrg.eu (A. Shams).
} 


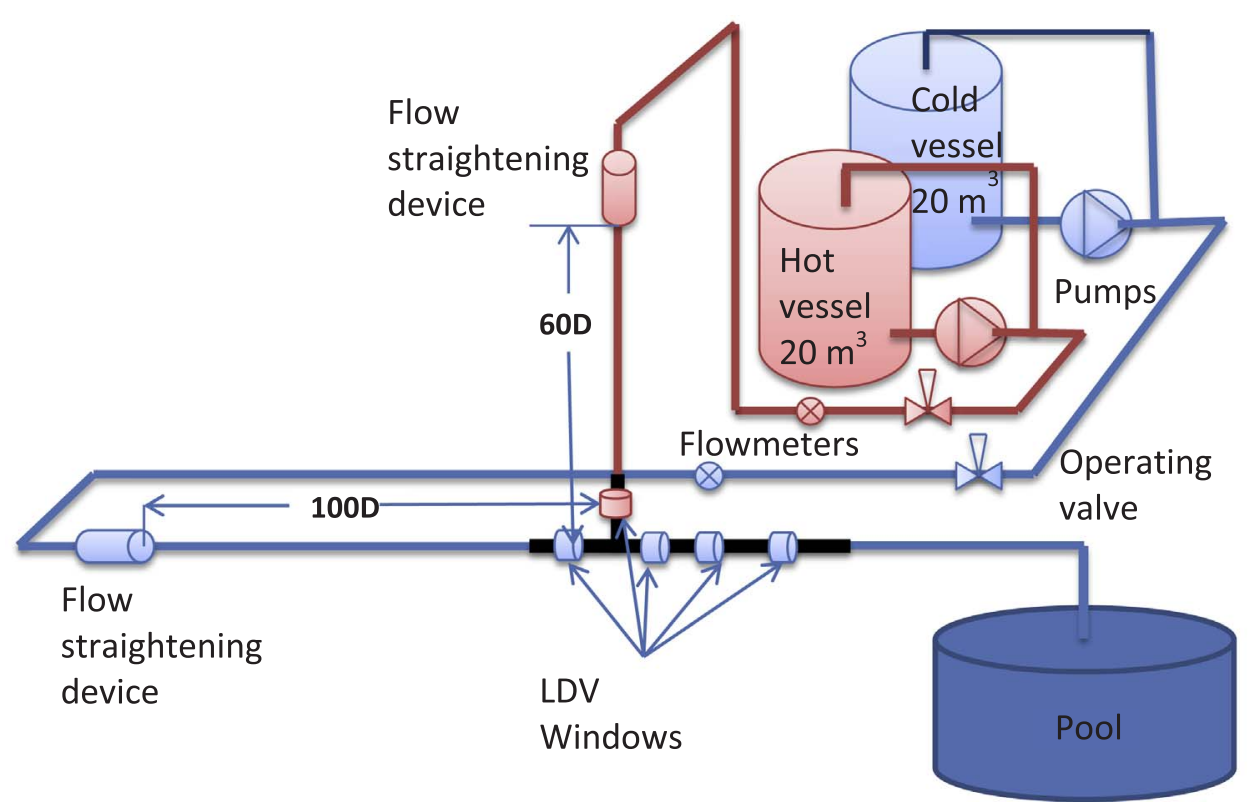

Fig. 1. The FATHERINO facility - overall view with the long straight pipes.

thermal loads for mixing in T-junction geometries. The instrumentation includes Laser Doppler Velocimetry (LDV) and thermocouples for the measurement of temperature. The advanced "coefh" sensor is used for the latter. The description of the FATHERINO test facility is given in Section 2. Details of the measurement techniques and the boundary conditions are given in Section 3. In Section 4, the results in the mixing region are reported. This is followed by the conclusions in Section 5 .

\section{The FATHERINO experimental setup}

The experimental setup is composed of an equal T-junction $(54 \mathrm{~mm} \times 54 \mathrm{~mm}$ in diameter $\mathrm{D})$ connected to two straight upstream pipes, i.e. a direct and a perpendicular branch, as shown in Fig. 1. The straight direct branch carries the cold water and is $100 \mathrm{D}$ long, whereas, the straight perpendicular branch is $60 \mathrm{D}$ long and carries the hot water. These pipes are composed of successive sections of PVC (polyvinyl chloride material) and stainless steel close to the T-junction and the whole system is connected by the flanges (Fig. 1).

Two independent pumps are installed to supply the flows to the Tjunction. In addition, two operating valves (controlled by the flow meters) are used to keep the flow rates constant during the decreasing water level in the respective vessels. The capacity of each vessel is $20 \mathrm{~m}^{3}$, which is sufficient in order to perform a test during several hours with the current flow rates.

In order to reduce the effects of the pipe bends, two flow straightening devices are installed before the straight pipes. These devices consist of cylinders with several long drilled parallel holes followed by three fine grids in order to generate evenly distributed velocity profiles with homogeneous turbulence.

\subsection{The mock-ups}

\subsubsection{The stainless steel $304 \mathrm{~L}$ mock-ups}

Two internal geometries are investigated, one sharp corner and one round corner, as shown in Fig. 2. The common dimensions for the 304L mock-ups are a nominal internal diameter of $54 \mathrm{~mm}$ with a thickness of $9.53 \mathrm{~mm}$. The diameter of the 304L mock-ups has been controlled and it has been found to be between $53.80 \mathrm{~mm}<\varnothing<53.97 \mathrm{~mm}$. The internal radius, $R$, of the roundness of the intersection between the two pipes is less than $1 \mathrm{~mm}$ for the sharp corner (i.e. can be assumed to be perfectly sharp in CFD) and $\mathrm{R}=18 \mathrm{~mm}$ for the round corner.

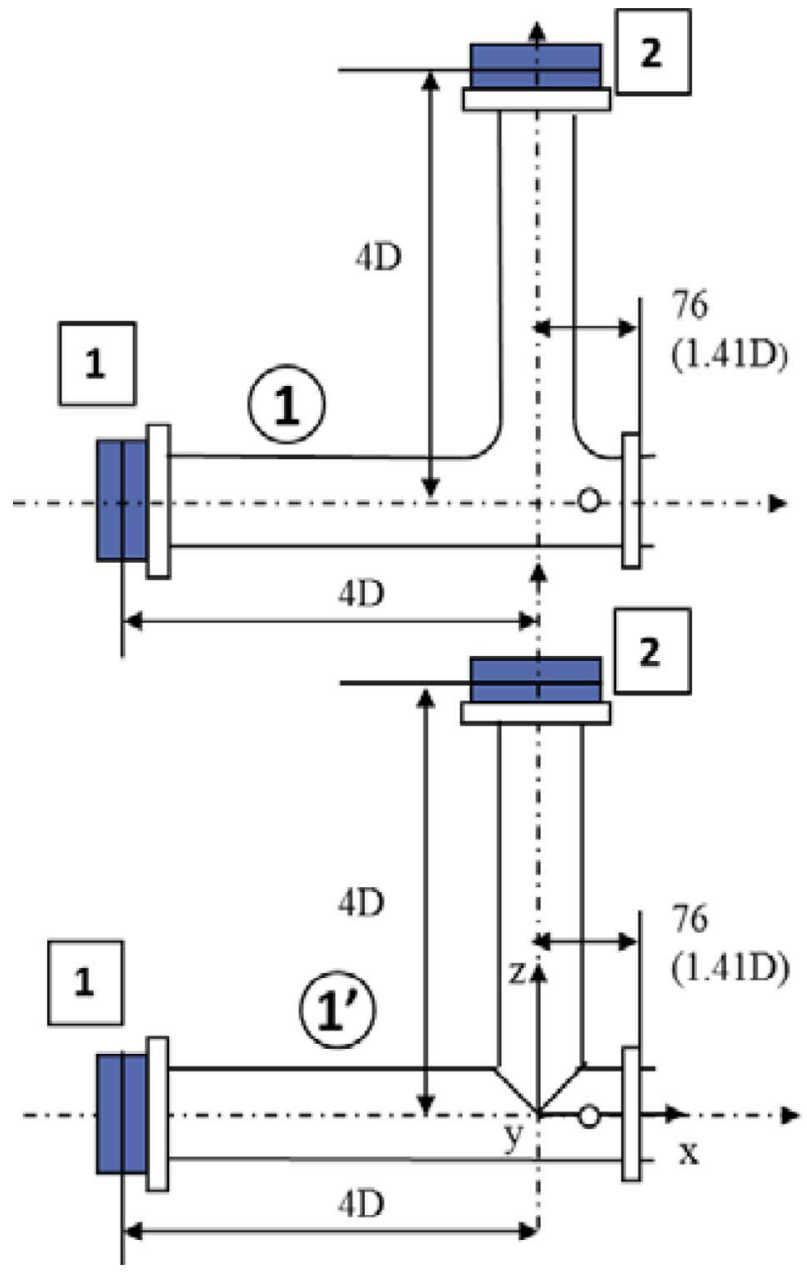

Fig. 2. The sharp and the round corner geometries.

The surface roughness has been measured (of the order of 1-10 $\mu \mathrm{m}$ ) and it can be concluded that it is safe to assume hydraulically smooth pipes in the CFD considering the values of the skin friction in the tests. The stainless steel is used for the mock-ups is $304 \mathrm{~L}$ with the following 


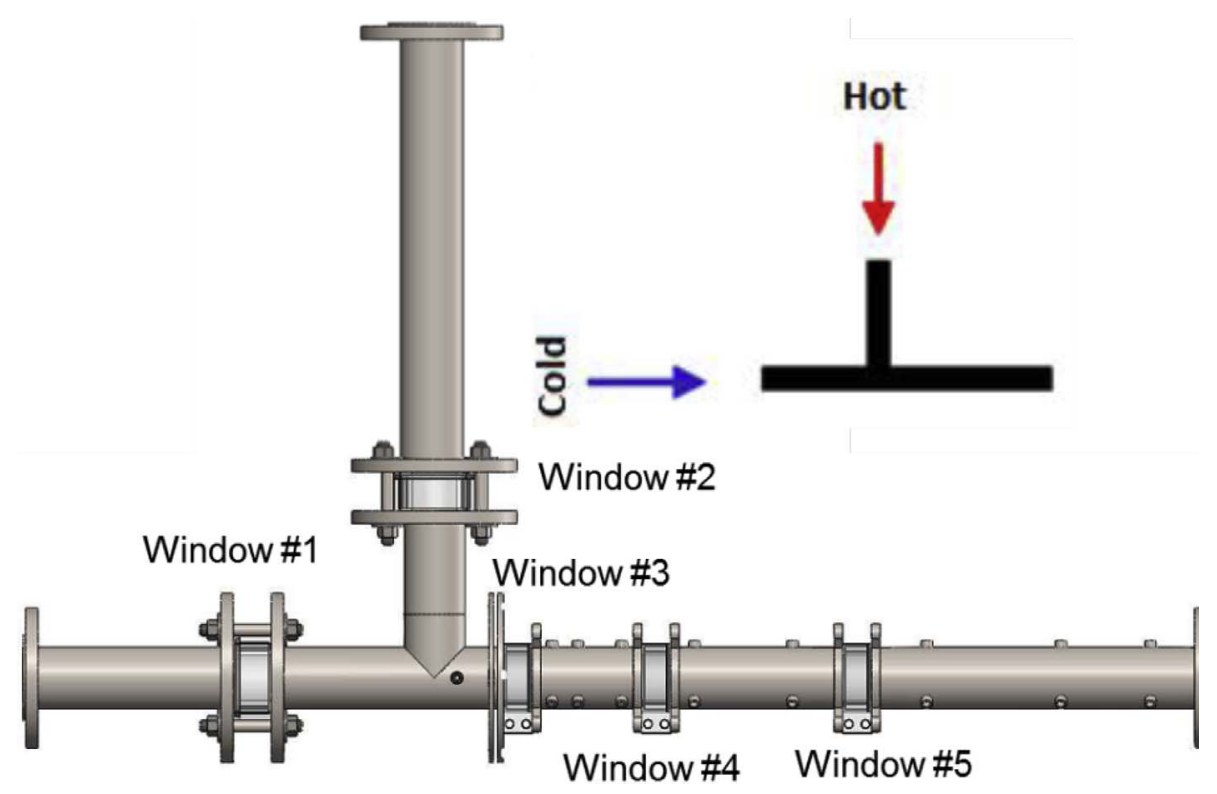

Fig. 3. 304L mock-up with 5 windows for the LDV measurements.

properties:

- Specific heat capacity: $\mathrm{c}_{\mathrm{p}}=460 \mathrm{~J} / \mathrm{kg} \cdot \mathrm{K}$

- Thermal conductivity: $\lambda=16 \mathrm{~W} / \mathrm{m} . \mathrm{K}$

- Density: $\rho=7821 \mathrm{~kg} / \mathrm{m}^{3}$

- Diffusivity: $\alpha=0.44510^{5} \mathrm{~m}^{2} / \mathrm{s}$

The overall view of the mock-up is shown Fig. 3 with the LDV windows. Two are located at the inlets and three in the mixing zone. To change the geometry between the round corner and the sharp corner, only the T-junction part is replaced.

The parts of the mock-ups are assembled by flanges. The LDV windows are inserted between the 304L pipes. The windows are nested with a centering counterbore. Two O-ring gaskets installed on the edges of each LDV window and assure the sealing and allow keeping an internal surface within a minimize gap of $0.3 \mathrm{~mm}$. The rotate part (number 3 ) is designed on the same principle (Fig. 4).

Each measurement section is equipped with two caps, one for the coefh-sensor and one for the fluid sensor. By rotating the pipe, various angles can be measured from $30^{\circ}$ to $150^{\circ}$ in steps of $20^{\circ}$. The uncertainty in the positioning of the angle is of the order of $1^{\circ}$. Some intermediate angles have been performed in the sensitive part of the mixing region $\left(80^{\circ}\right.$ and $\left.100^{\circ}\right)$, see Fig. 5. A right handed coordinate system is used as follows. The origin is where the axis of the main and branch pipe intersect. The $\mathrm{x}$-axis is defined as positive in the flow direction of the main pipe. The $\mathrm{z}$-axis is defined as positive such that gravity is in the negative z-direction.

\subsubsection{The brass mock-up}

The infrared measurements are performed with the brass mock-ups (round and sharp corner). Their internal geometries are identical to the 304L mock-ups, except the thickness reduced to $1 \mathrm{~mm}$ for providing the bandwidth of the thermal radiation. This mock-up is also called "the skin of the fluid" to remember that this thin structure like a skin is used as a frontier of the flow.

The brass mock-ups are used for temperature mapping in the mixing zone. The mock-ups supply local information to improve the knowledge on the effect of the corner. The brass mock-up favours a large diffusivity (factor 7.5 better than 304L).

Biot number $=\frac{h \cdot e}{\lambda}$

(h: heat transfer coefficient; e: thickness; $\lambda$ : wall conductivity). As the thickness is low $(1 \mathrm{~mm})$, the Biot number is low (less than

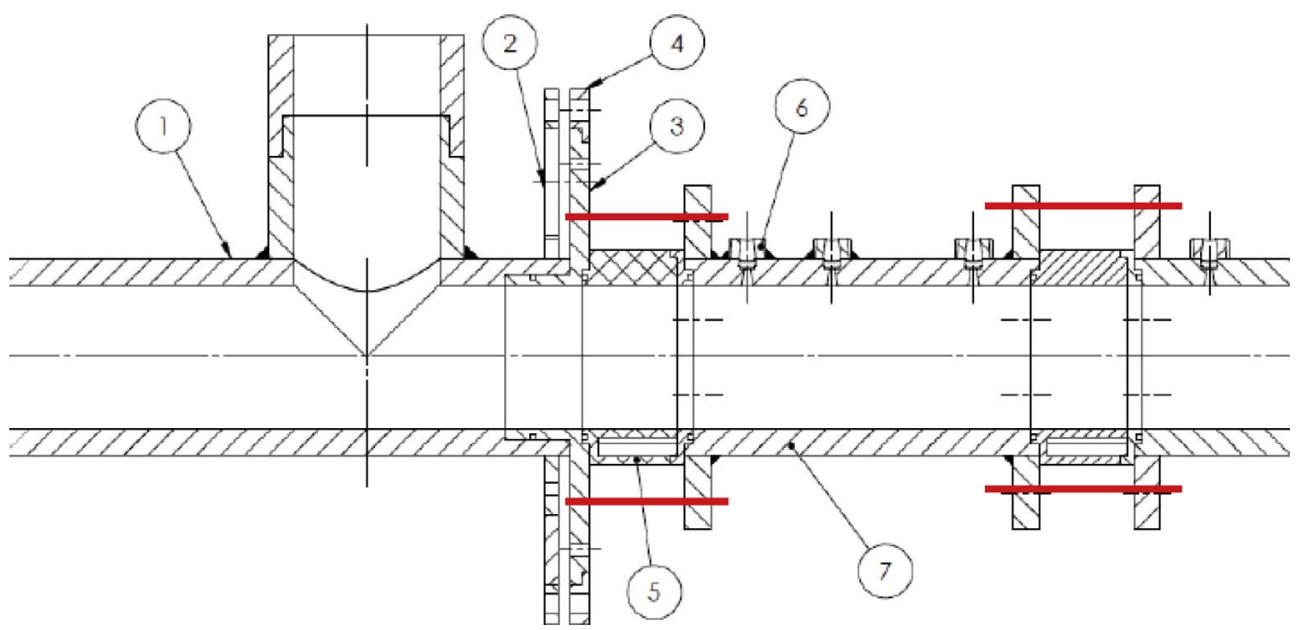

Fig. 4. Continuity of the internal surface between the connection of the LDV windows and the 304L pipes. 


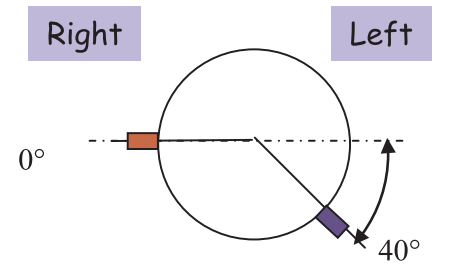

Angle : $90^{\circ}$

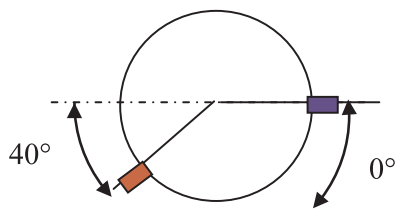

Angle : $130^{\circ}$

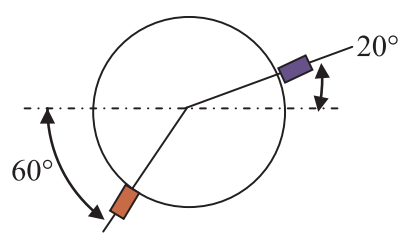

Angle : $150^{\circ}$

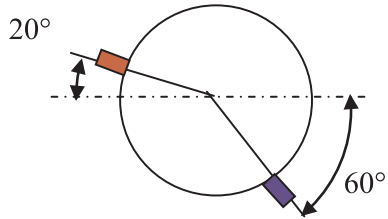

Angle : $70^{\circ}$

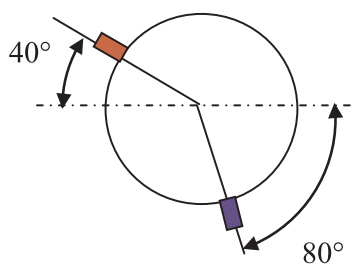

$80^{\circ}$

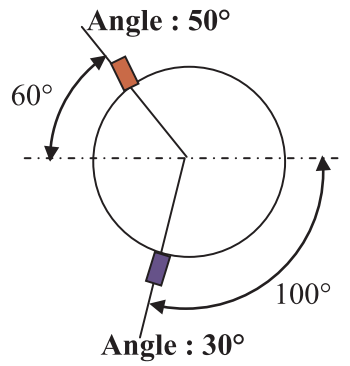

Angle : $30^{\circ}$

\section{- fluid sensor (2TC) Coefh sensor (4TC)}

Fig. 5. Angles in the azimuthal direction for the thermal instrumentation. Right and left sides are referenced by the views towards downstream.

0.05), that means the temperature fluctuating sampled between the inner and outer surface is weakly reduced. Nevertheless, the diffusivity in the perpendicular direction is also great and this effect in the perpendicular direction is not attenuated and reduces the sharpness of the infrared frames. The infrared camera is located in the mixing zone (closed and far from the tee junction to cover a large area of interest.

The common dimensions for the brass mock-up are a nominal internal diameter: $53 \mathrm{~mm}$ with a thickness: $1 \mathrm{~mm}$. For the brass mock-up, only the central part (i.e. the T-junction) is removed to switch between the configurations. The inlets straight pipes (vertical and horizontal) are connected to the junction part without welding as well as the outlet pipes. The overall dimensions of the brass mock-ups are similar to the 304L mock-ups. The main properties of the brass mock-ups are as follows:

- Heat mass: $385 \mathrm{~J} / \mathrm{kg} . \mathrm{K}$

- Thermal conductivity: $111 \mathrm{~W} / \mathrm{m} . \mathrm{K}$

- Density: $8522 \mathrm{~kg} / \mathrm{m}^{3}$

- Diffusivity: $3.38310^{-5} \mathrm{~m}^{2} / \mathrm{s}$

\section{Measurement techniques and boundary conditions}

\subsection{Mass flow rates}

The flowrates are measured by two conductivity flowmeters with an uncertainty of about $0.5 \%$ of full range $\left(0.15 \mathrm{~m}^{3} / \mathrm{h}\right)$. The devices have been calibrated against a Coriolis flowmeter by an external company qualified for the task. The cold and the hot flowrates are equal. Two Reynolds numbers were tested. The respective flowrate and bulk velocities are $2.95 \mathrm{~m}^{3} / \mathrm{h}$ giving an inlet bulk velocity of $0.36 \mathrm{~m} / \mathrm{s}$ and $4.35 \mathrm{~m}^{3} / \mathrm{h}$ giving a bulk velocity of $0.53 \mathrm{~m} / \mathrm{s}$. Note that all velocities are normalized with the bulk velocities in the mixing pipe, which is twice the mentioned velocities (more precisely $0.712 \mathrm{~m} / \mathrm{s}$ and $1.053 \mathrm{~m} / \mathrm{s}$, respectively).

\subsection{Fluid temperature at the hot and the cold inlets}

Two thermocouples measure the temperature at the inlets of the Tjunction (insulated K-type $\varnothing 0.5 \mathrm{~mm}$ ). The position in the fluid is fixed $3 \mathrm{~mm}$ from the wall. The uncertainty in such are of the order of $0.1-0.5^{\circ} \mathrm{C}$. The thermocouples are located at $9.9 \mathrm{D}$ before the T-junction for the direct (cold) line and 14.5 D for the perpendicular (hot) line, respectively. The cold and the hot nominal temperatures are $15^{\circ} \mathrm{C}$ and $30^{\circ} \mathrm{C}$, respectively. During many of the tests, the temperatures were slightly over the specified nominal values (approximately $1-2{ }^{\circ} \mathrm{C}$ ), which induces a slight increase in the Reynolds numbers. However, all results are normalized using $\Delta \mathrm{T}=\mathrm{T}_{\text {hot }}-\mathrm{T}_{\text {cold }}$ and are quite insensitive to small variations in the absolute values of the temperatures from day to day.

\subsection{Velocity profiles at the hot and the cold inlets}

Conventional LDV measurements are used for the velocity and turbulence measurements. In the mixing region, three windows filled with water are implemented at the axial distances $1.86 \mathrm{D}, 4.95 \mathrm{D}$, and 9.46 D for LDV measurements. The Plexiglas windows are separated by stainless steel sections.

The mock-ups have been equipped with five windows in Plexiglas (PMMA), two are located before the T-junction (at $x=-4 \mathrm{D}$ ) for measurements of the inlet boundary conditions and the others in the mixing area at three different distance downstream from the T-junction. The Plexiglas windows are filled with water for the laser beams to not be affected by the curved surface of the pipe geometry.

The typical duration for performing a LDV crossing is $20 \mathrm{~min}$ at $0.7 \mathrm{~m} / \mathrm{s}(\operatorname{Re}=40000$ and $35 \mathrm{~s}$ by point) and $15 \mathrm{~min}$ at $1.05 \mathrm{~m} / \mathrm{s}$ ( $R e=60000$ and $25 \mathrm{~s}$ by point). The number of valid data is collected. The criterion is reached when the sampling time or the number of valid data. When 100,000 valid points are recorded, the laser sensor moves automatically to the following location even if the sampling time is not reached. Basically, 100,000 data by point is rarely reached and the sampling time is often reached ( $35 \mathrm{~s}$ or $25 \mathrm{~s}$ ) before the 100,000 valid data. For the mixing area, the valid data by point for the channel 1 and channel 2 is taken as independent (non-coincidence option selected).

For the velocity profiles at the inlets, only one velocity component in the main direction of the flow was measured (however in two directions).

- Window \# 1 - horizontal line : U profile versus y-axis and z-axis

- Window \# 2 - vertical line : W profile versus y-axis and $\mathrm{x}$-axis

$U^{*}(R)=\frac{U(R)}{U_{\text {Bulk }}} \quad U_{R M S}^{*}(R)=\frac{U_{R M S}(R)}{U_{\text {Bulk }}}$

The velocity profiles corresponding to both Reynolds number are shown in Figs. 6 and 7. It can be concluded that the velocity profiles for the sharp corner and round corner at Re 40000 are very similar, see Fig. 6. In summary, a fully developed turbulent velocity profile can be assumed as a boundary condition (BC) for the CFD calculations (Fig. 8).

\subsection{Thermal measurements using the novel coefh-sensor}

The instrumentation is composed of two advanced temperature sensors in order to get the temperature measurements in the wall and in the fluid. The fluid sensors BF (304L) are composed of two thermocouples (K-type) $\varnothing 0.5 \mathrm{~mm}$ (time constant $=30 \mathrm{~ms}$ ) at the distances $2 \mathrm{~mm}$ and $5 \mathrm{~mm}$ from the wall, see Fig. 9.

The coefh-sensors are made of stainless steel 304L just like the Tjunction mock-ups. The three miniature K-type thermocouples $(\varnothing$ 

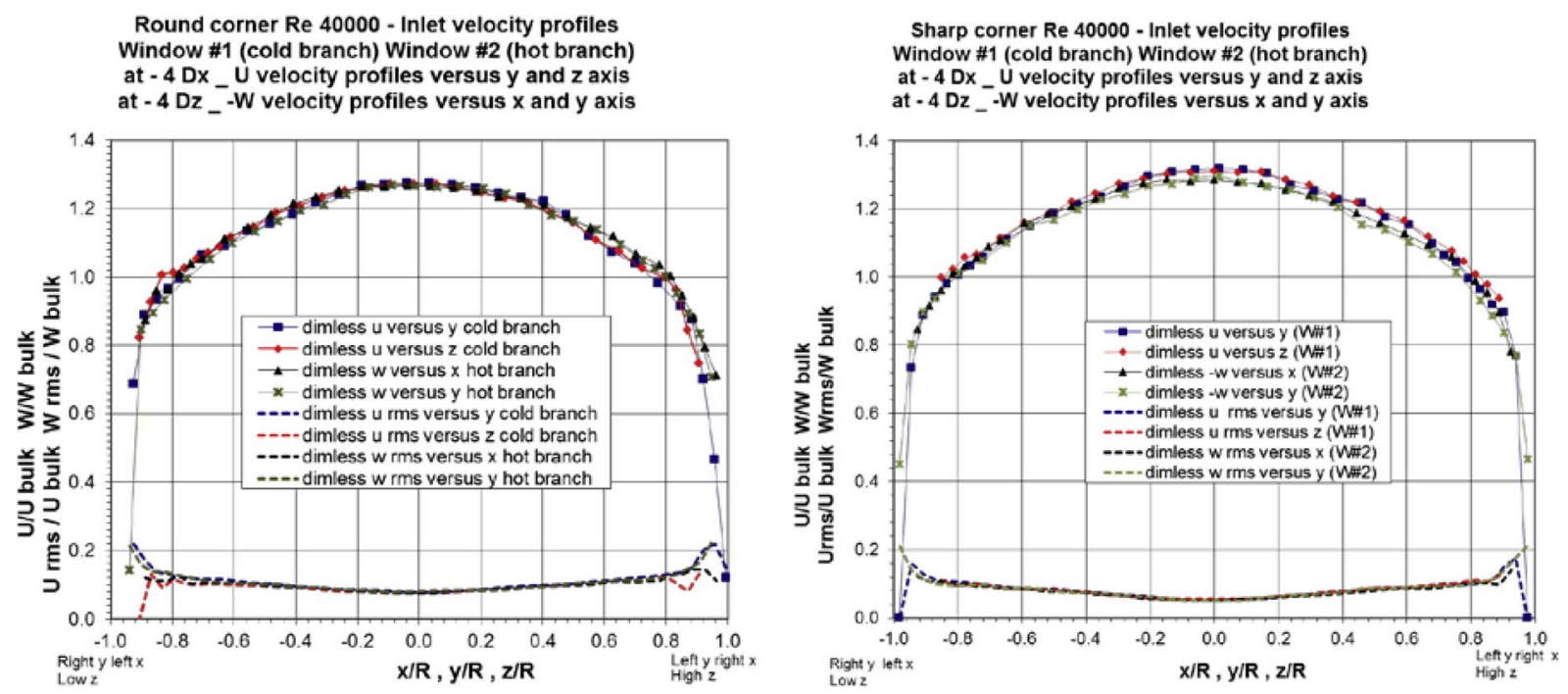

Fig. 6. Velocity profiles at the boundary conditions - Round corner (left) and Sharp corner (right) at $\mathrm{Re}=40000$ (U bulk $=0.36 \mathrm{~m} / \mathrm{s}$ ).

\begin{abstract}
Sharp corner Re 60000 - Inlet velocity profiles Window \#1 (cold branch) Window \#2 (hot branch) at $-4 \mathrm{Dx}$ _ $U$ velocity profiles versus $y$ and $z$ axis at $-4 \mathrm{Dz}{ }_{-}^{-}-W$ velocity profiles versus $x$ and $y$ axis
\end{abstract}

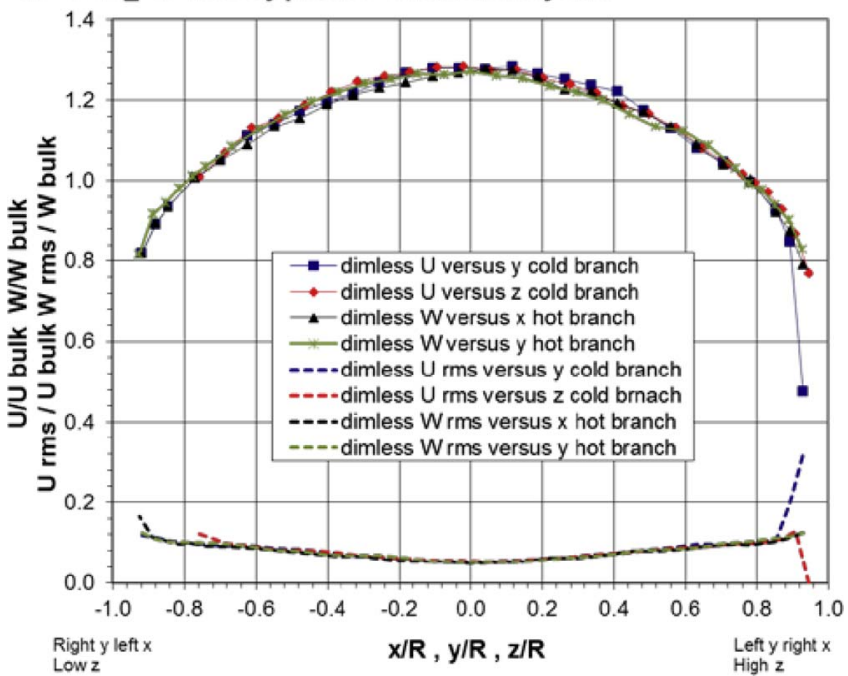

Fig. 7. Velocity profiles at the boundary conditions - Sharp corner at $\mathrm{Re}=60000 \mathrm{CU}$ bulk $=0.53 \mathrm{~m} / \mathrm{s})$.

$25 \mu \mathrm{m})$ are located at three distances from the wall $(0.4 \mathrm{~mm}, 1.4 \mathrm{~mm}$ and $2.5 \mathrm{~mm})$. One thermocouple $\mathrm{K}$ type $(\varnothing 0.3 \mathrm{~mm})$ is located inside the fluid at a distance $2 \mathrm{~mm}$ from the wall (Fig. 9). The time constant of the miniature K-type thermocouple is $30 \mu$ s and $10 \mathrm{~ms}$ for the $\mathrm{K}$ type thermocouple in the fluid. The accuracy of the coefh sensor depends of several factor but for the dynamic response, the most important is the perfect knowledge of the distance from the wall of the 3 miniature thermocouples. During the manufacturing, the binocular is used to make measurements with accuracy.

The instrumentation is composed of five coefh-sensors located on the right side of the test section and four fluid sensors at the same axial distances from the T-junction but on the left side of the pipe. The two rows of caps are welded at $110^{\circ}$, which corresponds to the symmetrical azimuthal angle for the coefh and the fluid sensors (BF), see Fig. 10. To vary and select the different azimuthal angles specified in Fig. 5 during the measurements, the mixing pipe can be rotated around its $\mathrm{x}$-axis without stopping the test rig.

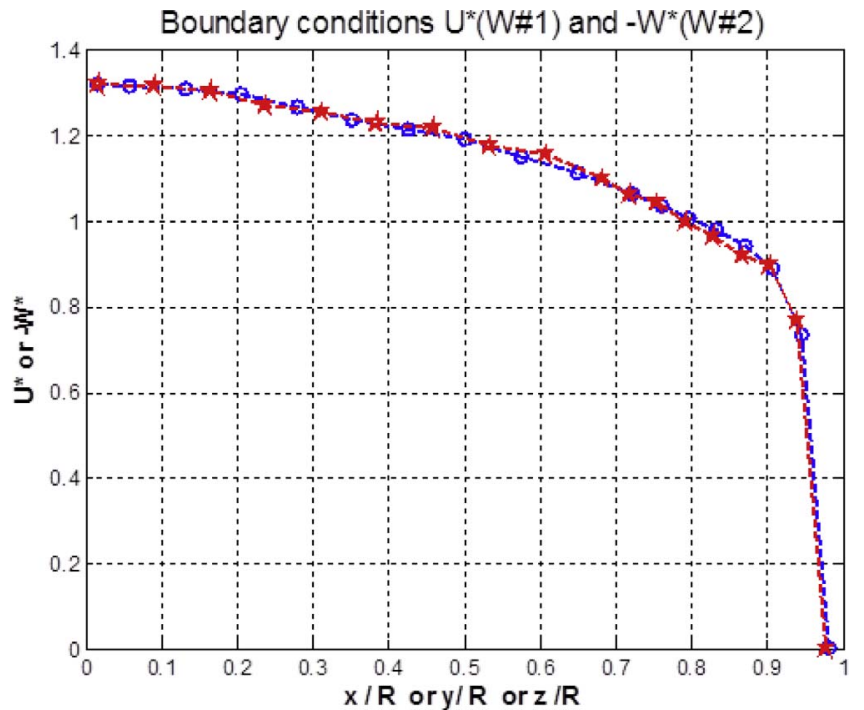

Fig. 8. Inflow velocity boundary conditions by the (Blue line) Reynolds law model (Red line) LDV measurements. (For interpretation of the references to colour in this figure legend, the reader is referred to the web version of this article.)

\subsection{Sensors implementation in the mixing zone}

The sensors implemented in the mixing zone cover an area from $2.62 \mathrm{D}$ to $8 \mathrm{D}$ (Table 1 ). The coefh sensor located at $0.5 \mathrm{D}$ (in the Tjunction) is used to verify that the temperatures are similar for the three configurations.

\section{Results in the mixing region}

\subsection{Velocity measurements}

Figs. 11-13 display the velocity profiles and their RMS's along the yaxis. It can be observed that in the mixing zone closest to the T-junction, at $1.86 \mathrm{D}$, the difference in the velocity profiles is large between the sharp and the round corner. The U(y)-profile has a large wake with locally lower velocity for the sharp corner contrary to the round corner configuration. The separation zone just behind the vertical line (1.86 D) on the both sides of the $\mathrm{x}$ axis is not located at the same position if one compares the U(z)-plots in Figs. 14-16. The Reynolds number does not have a large effect on the velocity profiles for the sharp corner 

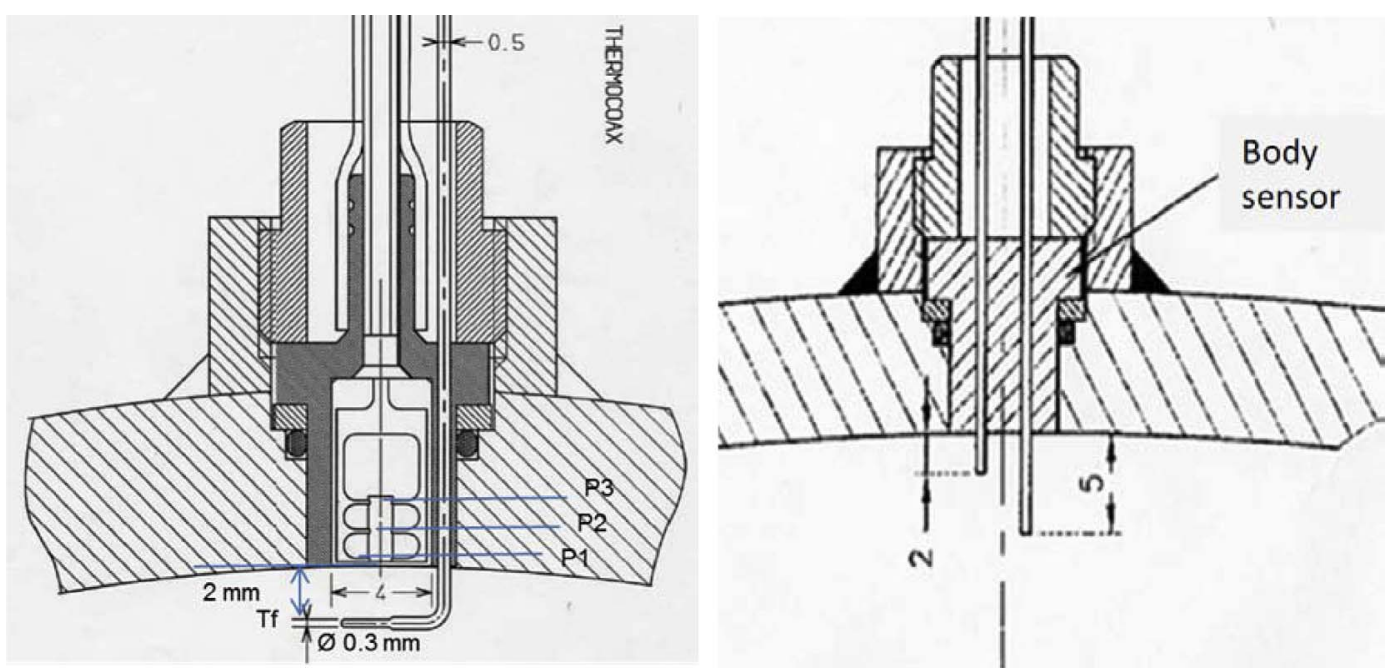

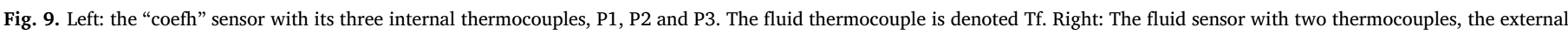
body is identical to the coefh sensor.

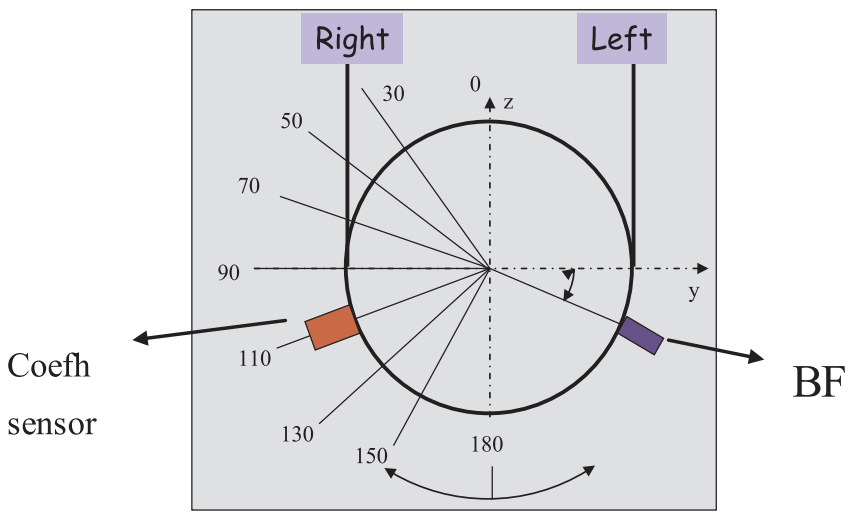

Fig. 10. Implementation of the rows of sensor caps in the T-junction mixing area.

configuration at any position. The relaxation downstream towards a more uniform velocity profile seem to be faster for the round corner configuration.

$U^{*}(R)=\frac{U(R)}{U_{\text {Bulk }}} \quad U_{R M S}^{*}(R)=\frac{U_{R M S}(R)}{U_{\text {Bulk }}}$

\subsection{RMS of fluid and solid temperature}

The thermal field is non-dimensionalized as follows:

$T^{*}=\frac{T-T f_{\text {Cold }}}{T f_{\text {Hot }}-T f_{\text {Cold }}}$
$T_{R M S}^{*}=\frac{T_{R M S}}{T f_{\text {Hot }}-T f_{\text {Cold }}}$

For all the thermal tests, the parameters selected for the data acquisition are:

- Acquisition duration: $10 \mathrm{~min}$

- Sampling frequency: $80 \mathrm{~Hz}$

The PSD outputs from the temperature measurements in the mixing area are computed upon the following parameters:

- Block size: 1024 pts

- Weighting window: Hanning

- Frequency resolution: $0.078 \mathrm{~Hz}$

- Frequency bandwidth: $40 \mathrm{~Hz}$

- Number of averaged PSD: 45

- Overlap block: 50\%

It is worthwhile to mention that the $\mathrm{T}_{\mathrm{w}}$ is the deduced value at the inner wall surface temperature by the inverse conduction method. In the range of interest for the CFD-simulations, the RMS temperatures in the fluid and in the solid were computed for the three configurations as a function of the azimuthal angle at four distances $(2.62 \mathrm{D}, 4.18 \mathrm{D}$, 5.8 D, and 8D) from the T-junction (see Figs. 17-19). In the fluid, the difference between the configurations is small, the maximum values are more centered around $60^{\circ}$ for the round corner case and $90^{\circ}$ for the sharp corner case. The main difference is the temperature in the solid, which is largely attenuated for the round corner compared to the sharp corner. This could be interpreted as a higher heat transfer from the fluid to the wall in the sharp corner case. The maximum fluctuation in the

Table 1

Thermal instrumentation in the mixing zone - location of the LDV measurements.

\begin{tabular}{|c|c|c|c|c|}
\hline & $\begin{array}{l}\text { Distance from the vertical axis of the perpendicular line } \\
(\mathrm{D}=54 \mathrm{~mm})\end{array}$ & $\begin{array}{l}\text { Distance from the vertical axis of the } \\
\text { perpendicular line (mm) }\end{array}$ & $\begin{array}{l}\text { Coefh sensor right } \\
\text { side }\end{array}$ & $\begin{array}{l}\text { Fluid sensor left } \\
\text { side }\end{array}$ \\
\hline S0 - Tee \#1 \& $1^{\prime}$ & $0.5 \mathrm{D}$ & 27 & \multicolumn{2}{|l|}{ Coefh03 } \\
\hline Window \#3 & $1.86 \mathrm{D}$ & 100 & \multicolumn{2}{|c|}{$\mathrm{LDV}-\mathrm{y}$ axis and $\mathrm{x}$ axis } \\
\hline S1' - Mixing section & $2.62 \mathrm{D}$ & 141.5 & Coefh05 & BF02 \\
\hline S3 - Mixing section & $4.18 \mathrm{D}$ & 225.6 & Coefh07 & BF03 \\
\hline Window \#4 & $4.95 \mathrm{D}$ & 268 & \multicolumn{2}{|c|}{$\mathrm{LDV}-\mathrm{y}$ axis and $\mathrm{x}$ axis } \\
\hline S5 - Mixing section & $5.8 \mathrm{D}$ & 313.3 & Coefh20 & BF04 \\
\hline S7 - Mixing section & $8 \mathrm{D}$ & 432 & Coefh21 & BF05 \\
\hline Window \#5 & $9.46 \mathrm{D}$ & 511 & \multicolumn{2}{|c|}{ LDV $-\mathrm{y}$ axis and $\mathrm{x}$ axis } \\
\hline
\end{tabular}



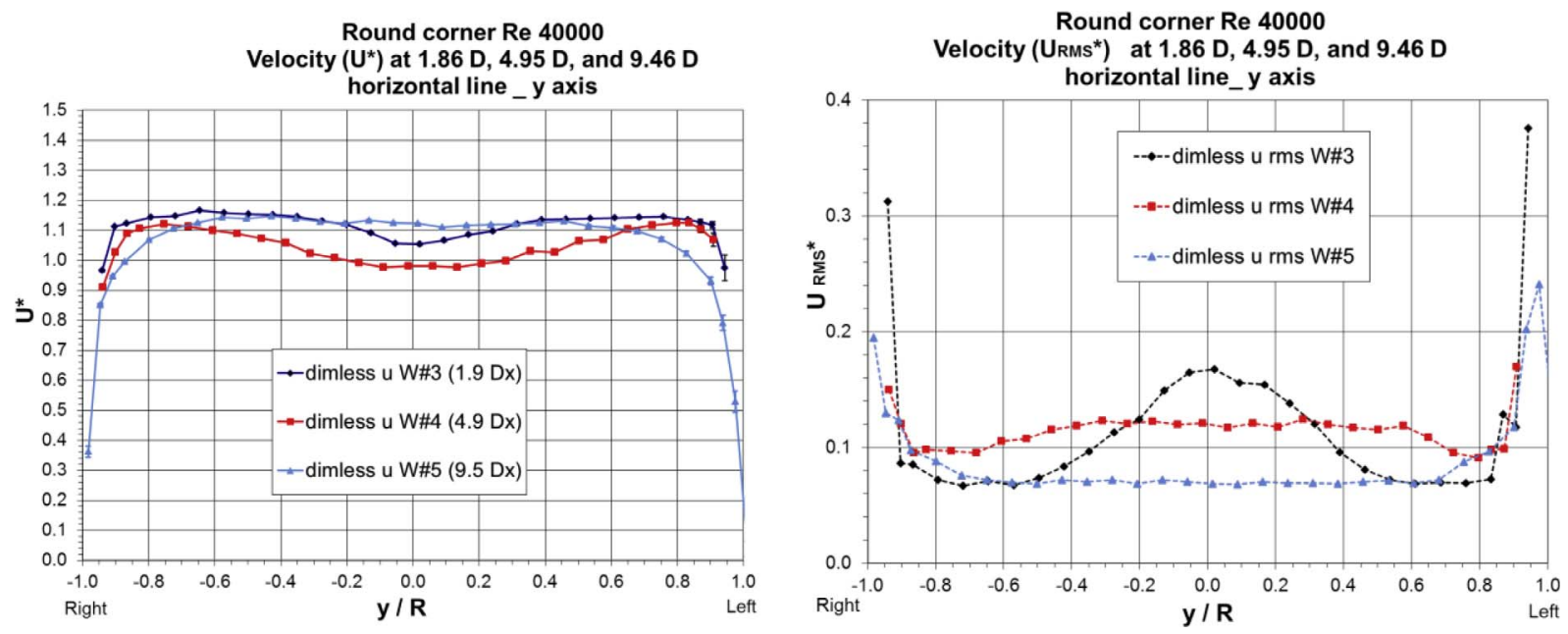

Fig. 11. $U^{*}$ and URMS $^{*}$ versus $y$-axis for the round corner with $R e=40000$ configuration at $1.86 \mathrm{D}, 4.95 \mathrm{D}$, and $9.46 \mathrm{D}\left(\mathrm{U}_{\mathrm{bulk}}=0.71 \mathrm{~m} / \mathrm{s}\right)$.

round corner case is obtained at $4.18 \mathrm{D}$ and not at $2.62 \mathrm{D}$ as in the sharp corner case. The increase of the Reynolds number for the sharp corner case enhances the heat transfer as the RMS temperature in the solid increases from 0.023 to 0.033 , while the fluctuation in the fluid remains practically the same (Figs. 18 and 19).

\subsection{Fluid and solid temperature power spectral density}

The power spectral density (PSD) has been computed from the coefh-sensor data. The PSD in Fig. 20 shows five curves, the three measurements in the solid (P1, P2, P3) and one in the fluid (Tf). In addition, the wall temperature (Tw-inv) is computed by solving the inverse heat conduction problem upon a $1 \mathrm{D}$ assumption. The time histories from the thermocouples $[Y(t)]_{i=1,2,3}$ are collected and a sequential inverse conduction algorithm is used to assess the fluctuating heat flux $q(t)$ at the wall-fluid limit at $x=0$. The method is based on the concepts of "future time-step" and "function specification" (Equation (3)). It means that the heat flux at the time $q\left(t_{k}\right)$ is computed from the temperature measurements later than $t_{k}$.

Equation 3: Inverse conduction algorithm.

$q\left(t_{k+1}\right)=q\left(t_{k}\right)+\sum_{k=1}^{r} \sum_{i=1}^{2}\left[Y_{i}\left(t_{k}\right)-\widehat{T}_{i}\left(t_{k}\right)\right] / K_{i}^{k}$

where

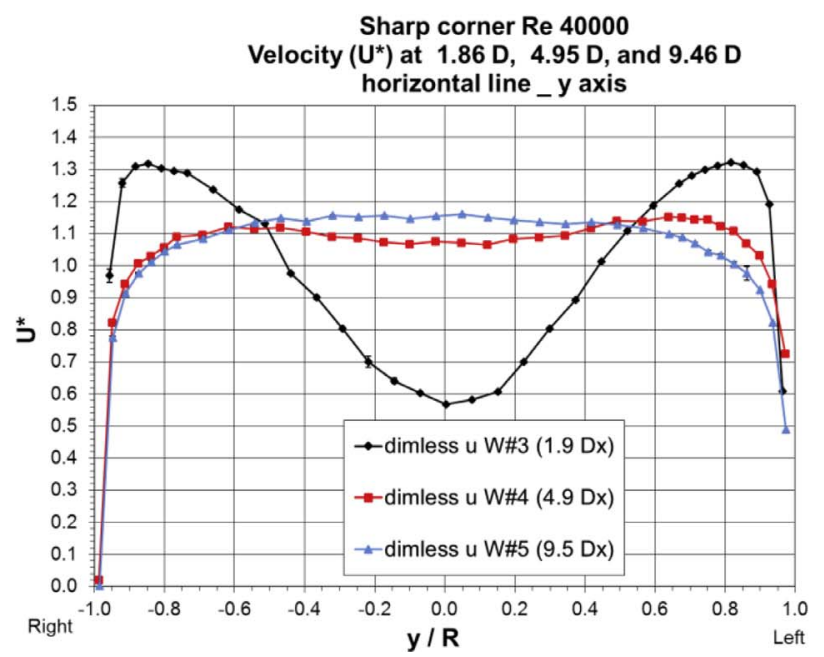

$K_{i}^{k}$ are sensitivity coefficients which depends of the TC locations, $r$ is the number of future time steps,

$\widehat{T}_{i}$ is the temperature computed from the one-dimensional heat conduction equations

Also shown is the temperature in the fluid (Tf-non att.) as being the temperature signal without attenuation due to its time constant. For all the thermal tests, the parameters selected for the data acquisition are an acquisition time of $10 \mathrm{~min}$ at a sampling frequency of $80 \mathrm{~Hz}$. The PSD's are computed based on the following parameters: a block size of 1024 points, a Hanning weighting window, an averaging of 45 blocks and a block overlap of $50 \%$.

The first observation is the presence of a peak in the PSD in the fluid. This peak was only observed for the sharp corner configuration (Figs. 20 and 21). It is located at $6 \mathrm{~Hz}$ for the low Reynolds number case and it is increased to $9.2 \mathrm{~Hz}$ for the high Reynolds number case, however, if non-dimensionalized, the Strouhal number St is constant and around 0.5. This peak was also observed further downstream, at $4.18 \mathrm{D}$, $5.8 \mathrm{D}$, however with a reduction in the amplitude.

$S t=\frac{f D}{V}$

(f: frequency $(\mathrm{Hz})-\mathrm{D}$ diameter $(\mathrm{m})-\mathrm{V}$ bulk velocity $(\mathrm{m} / \mathrm{s})$ ).

In the solid, the PSD of the first thermocouple close to the wall (P1) shows the same peak at the same frequency. However, this peak has weak amplitude. In P2 it is even weaker and it is fully attenuated in P3.

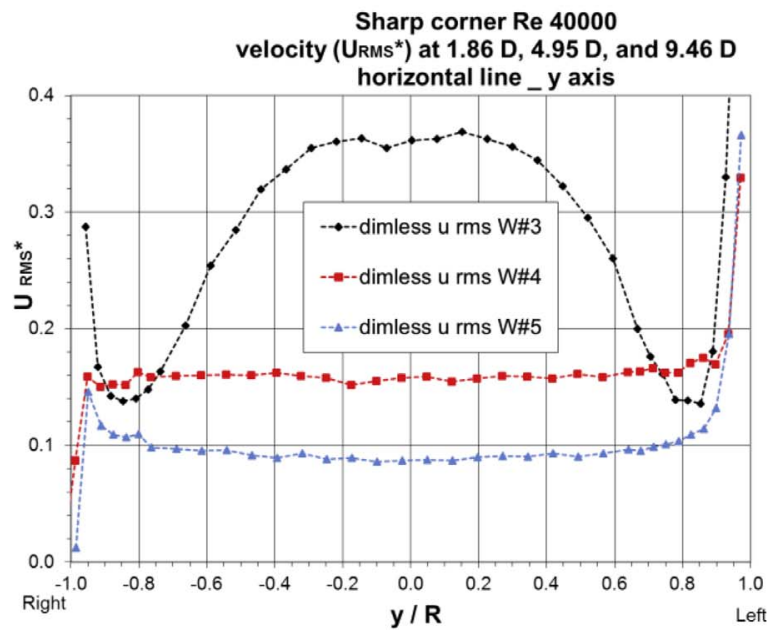

Fig. 12. $\mathrm{U}^{*}$ and $\mathrm{URMS}^{*}$ versus $\mathrm{y}$-axis for the sharp corner with $\mathrm{Re}=40000$ configuration at $1.86 \mathrm{D}, 4.95 \mathrm{D}$, and $9.46 \mathrm{D}\left(\mathrm{U}_{\mathrm{bulk}}=0.71 \mathrm{~m} / \mathrm{s}\right)$. 

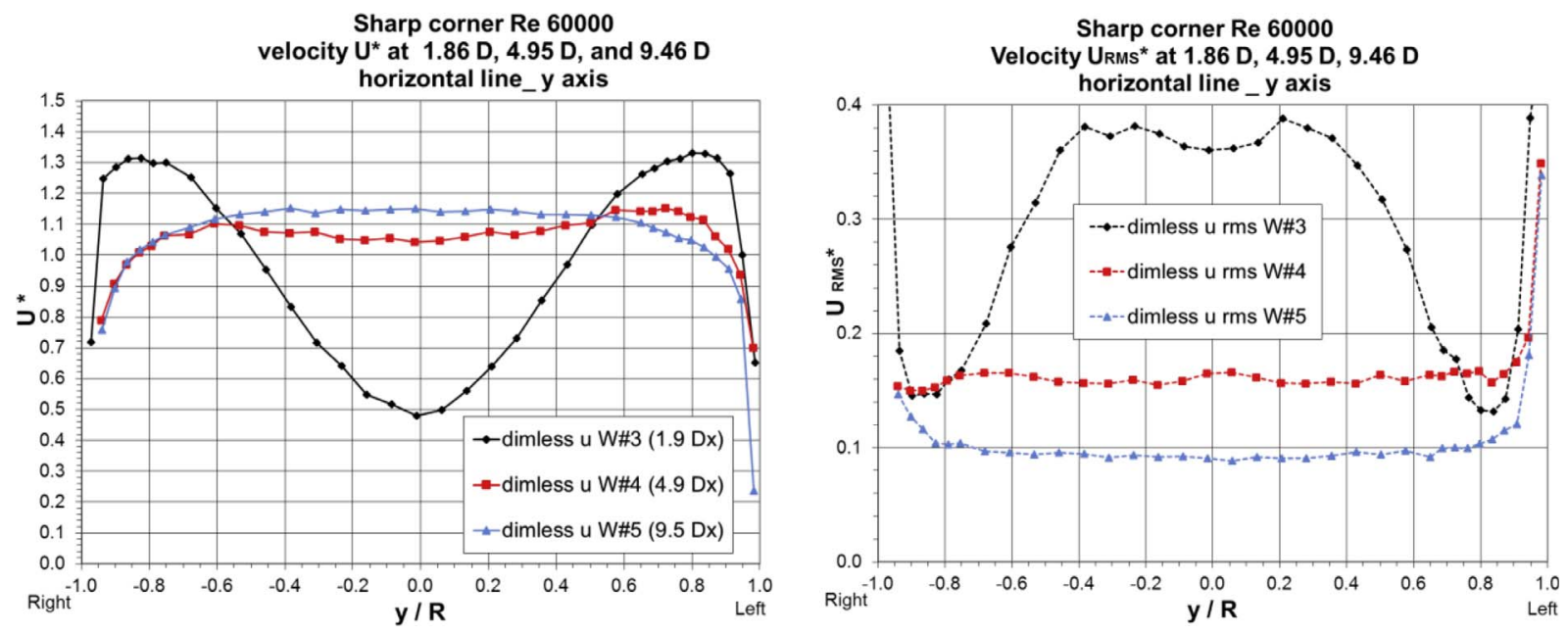

Fig. 13. $\mathrm{U}^{*}$ and $\mathrm{URMS}^{*}$ versus $\mathrm{y}$-axis for the sharp corner with $\mathrm{Re}=60000$ configuration at $1.86 \mathrm{D}, 4.95 \mathrm{D}$, and $9.46 \mathrm{D}\left(\mathrm{U}_{\text {bulk }}=1.05 \mathrm{~m} / \mathrm{s}\right)$.
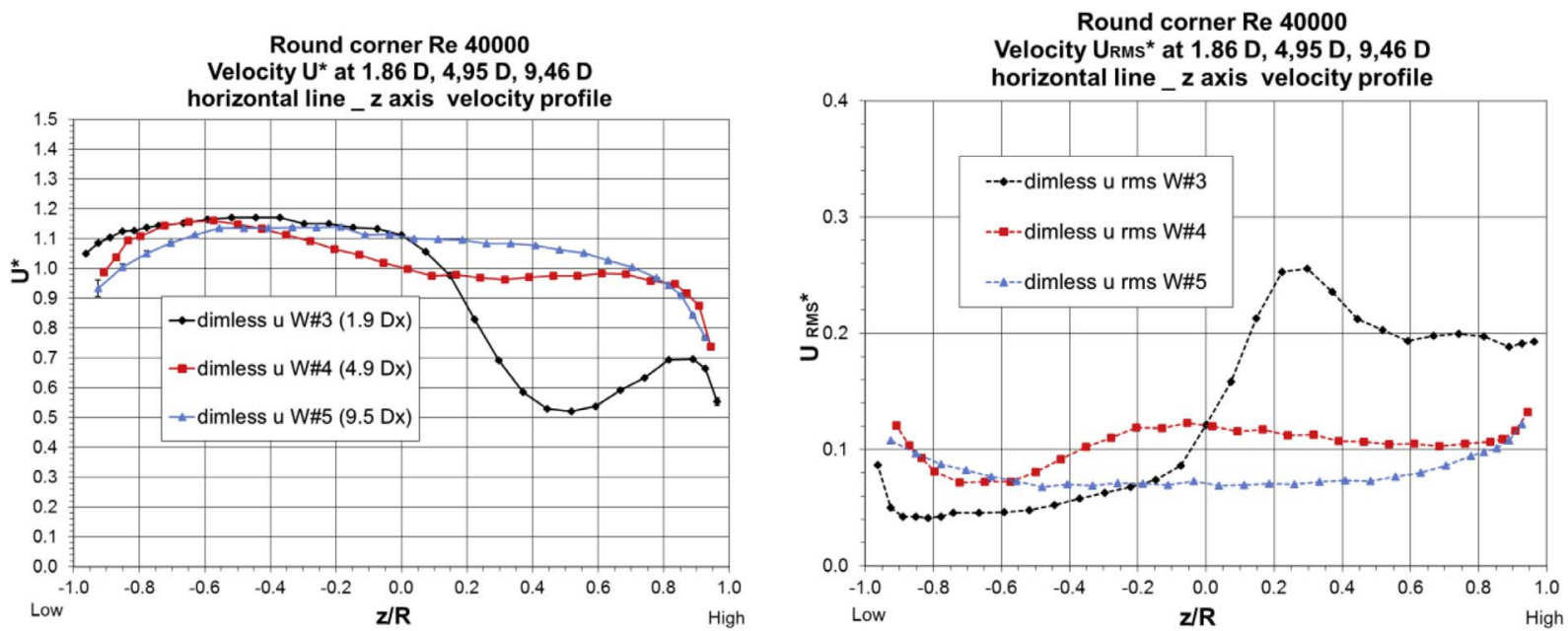

Fig. 14. $U^{*}$ and URMS" versus z-axis for the round corner with $R e=40000$ configuration at $1.86 \mathrm{D}, 4.95 \mathrm{D}$, and $9.46 \mathrm{D}\left(\mathrm{U}_{\mathrm{bulk}}=0.71 \mathrm{~m} / \mathrm{s}\right)$.
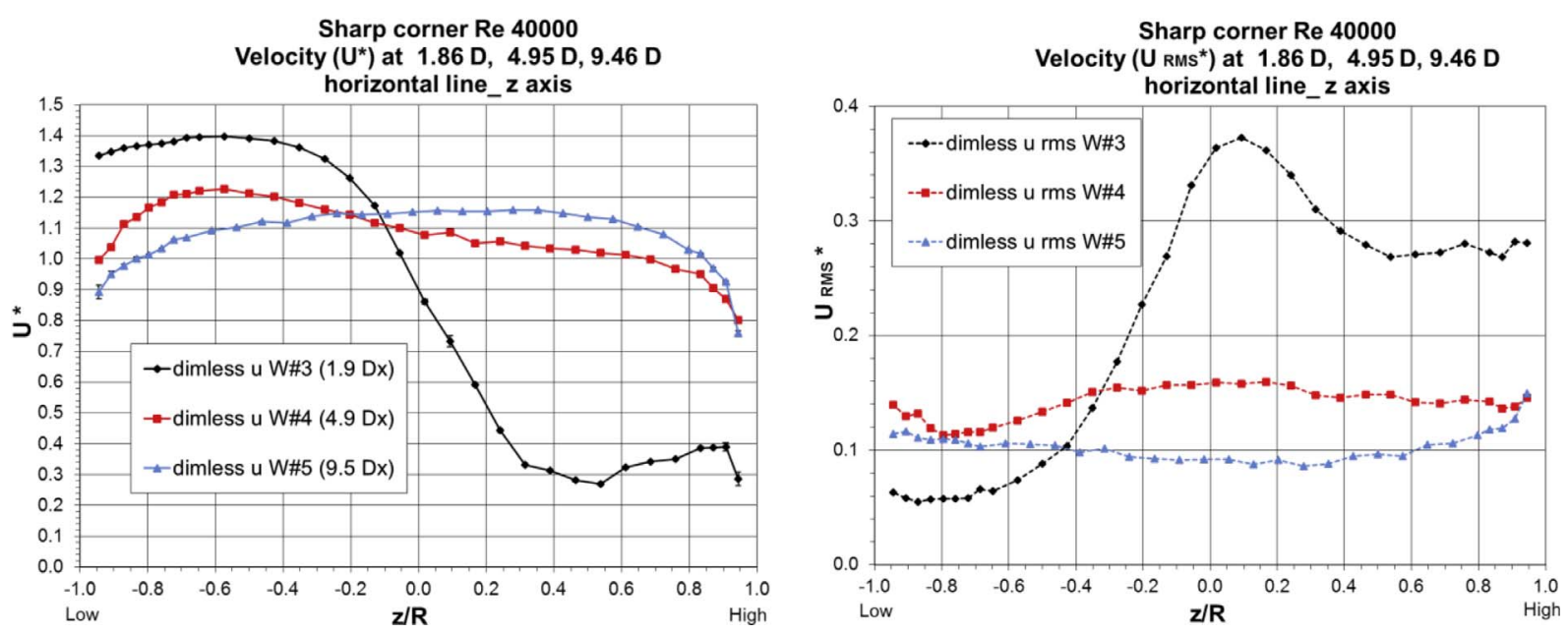

Fig. 15. $U^{*}$ and URMS* versus z-axis for the sharp corner with $R e=40000$ configuration at $1.86 \mathrm{D}, 4.95 \mathrm{D}$, and $9.46 \mathrm{D}\left(\mathrm{U}_{\mathrm{bulk}}=0.71 \mathrm{~m} / \mathrm{s}\right)$.

Thermal peak is not observed in the RC configuration (Fig. 21). When studying the PSD at different azimuthal angles at $2.62 \mathrm{D}$, the peak is only observed from $30^{\circ}$ to $110^{\circ}$ but not at $130^{\circ}$ and $150^{\circ}$. This is changed in the downstream direction as the mixing layer is inclined. To the authors knowledge, this is the first time a peak has been observed for an equal tee configuration. Earlier, a peak has only been observed when the diameters of the two pipes in the T-junction are different. The peak does not occur for the round corner configuration where the separation point is not fixed in space and the shear layer vortex shedding is less pronounced. 

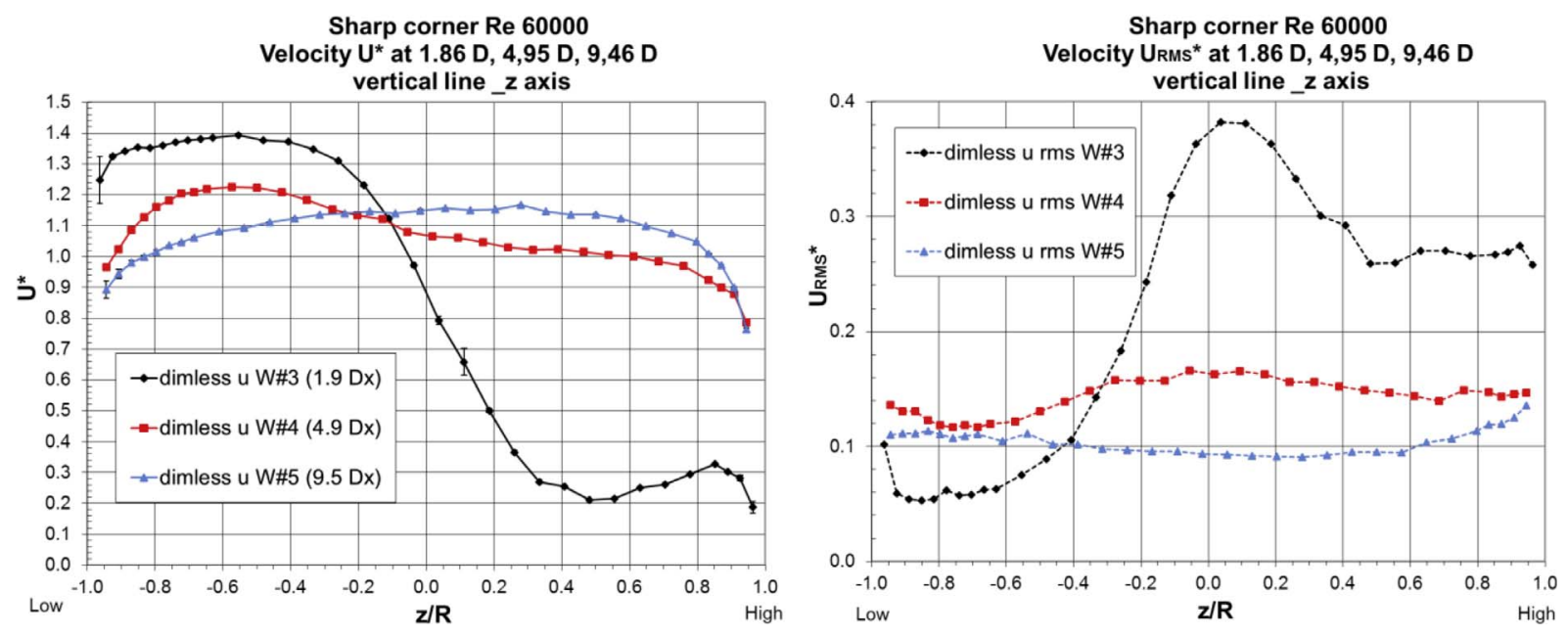

Fig. 16. $U^{*}$ and $U R M S^{*}$ versus z-axis for the sharp corner with $R e=60000$ configuration at $1.86 \mathrm{D}, 4.95 \mathrm{D}$, and $9.46 \mathrm{D}\left(\mathrm{U}_{\mathrm{bulk}}=1.05 \mathrm{~m} / \mathrm{s}\right)$.

Tf dimless (RMS) - from $1 \mathrm{~Hz}$ to $10 \mathrm{~Hz}$ Round Corner Re 40k

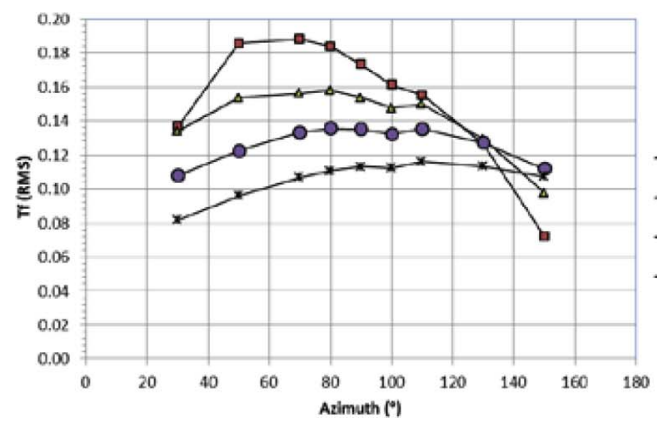

Tw dimless (RMS) - from $1 \mathrm{~Hz}$ to $10 \mathrm{~Hz}$ Round Corner Re 40k

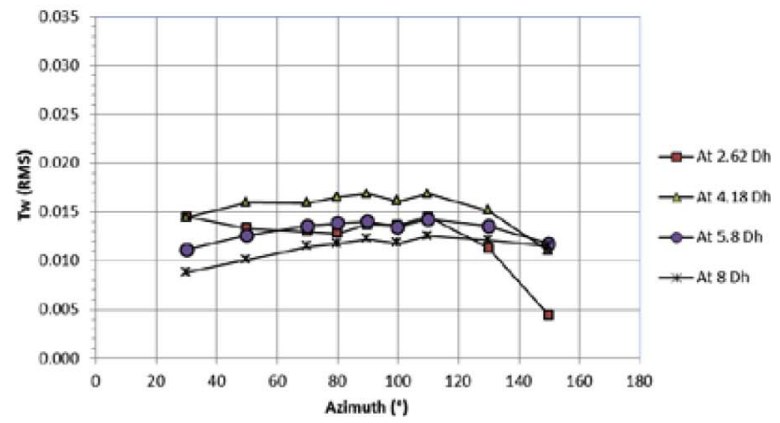

Fig. 17. RMS temperature in the fluid (Tf) and in the solid (Tw) - bandwidth $(1 \mathrm{~Hz}-10 \mathrm{~Hz})-$ round corner at $\mathrm{Re}=40000$.
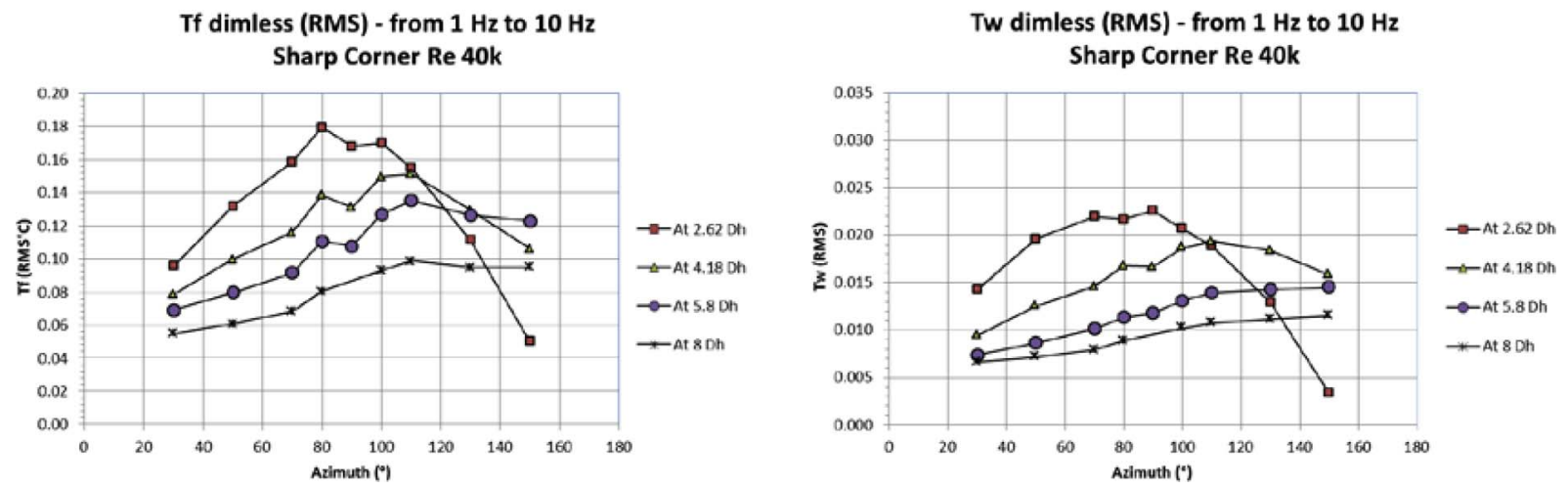

Fig. 18. RMS temperature in the fluid (Tf) and in the solid (Tw) - bandwidth $(1 \mathrm{~Hz}-10 \mathrm{~Hz})-$ sharp corner at Re $=40000$.

\subsection{Infrared temperature measurements}

The brass mock-up is installed with the same straight parts at the hot and cold side inlets, respectively. The part of interest in the mixing region is divided into two areas for the infrared measurements (as shown in Fig. 22).

The first area for infrared measurements (\#100) from $X=-D$ to $\mathrm{X}=4.7 \mathrm{D}$ includes the T-junction and the beginning of the mixing pipe. The area covers the LDV window \#3 $(1.86 \mathrm{D})$ and the thermal measurements of the coefh sensor located in section \#1 (2.62 D) and the section \#2 (4.18D). The second infrared area (\#200 view) from $\mathrm{X}=4.6 \mathrm{D}$ to $\mathrm{X}=10 \mathrm{D}$ includes the streamwise development of the mixing area. The area covers the LDV window \#4 $(\mathrm{X}=4.95 \mathrm{D})$ and the \#5 $(X=9.46 \mathrm{D})$ and also the thermal measurements of the coefh sensors located in the sections S5 and S7 (at X $=5.8 \mathrm{D} \& \mathrm{X}=8 \mathrm{D}$ ). The time recording for an infrared (IR) test is $180 \mathrm{~s}$ and the sampling frequency is $50 \mathrm{~Hz}$. Each acquisition contains a standard frame $320 \times 240$ pixels.

Three configurations are tested (Fig. 23):

1. Brass material round corner - Re 40000 - test \#401

2. Brass material sharp corner - Re 40000 - test \#501

3. Brass material sharp corner - Re 60000 - test \#601

The pixels of interest can be selected from the infrared software application to plot the time histories of each pixel. Each IR section contains 14 pixels distributed on $180^{\circ}$. Among them, 11 pixels are selected corresponding to the azimuthal angles: 
Tf dimless (RMS) - from $1 \mathrm{~Hz}$ to $10 \mathrm{~Hz}$ Sharp Corner Re 60k

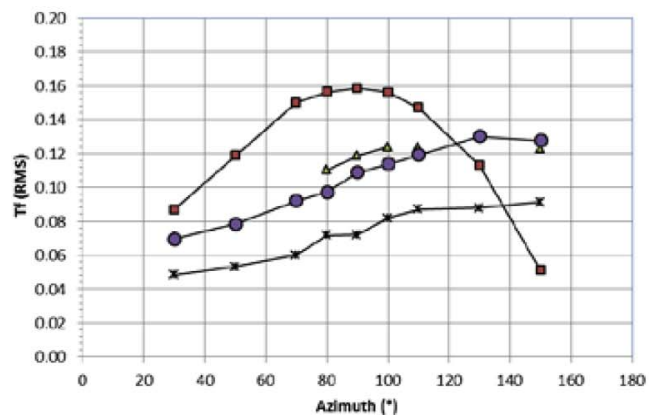

Tw dimless (RMS) - from $1 \mathrm{~Hz}$ to $10 \mathrm{~Hz}$ Sharp Corner Re 60k

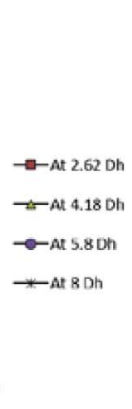

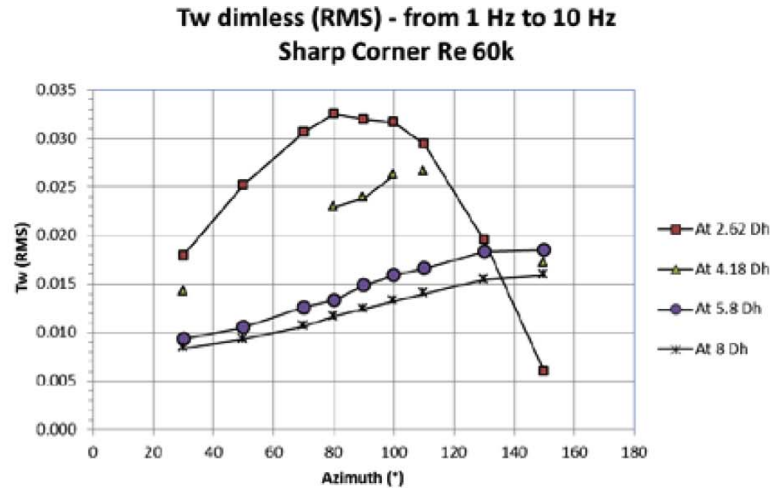

Fig. 19. RMS temperature in the fluid (Tf) and in the solid (Tw) - bandwidth $(1 \mathrm{~Hz}-10 \mathrm{~Hz})-$ sharp corner at $\mathrm{Re}=60000$.
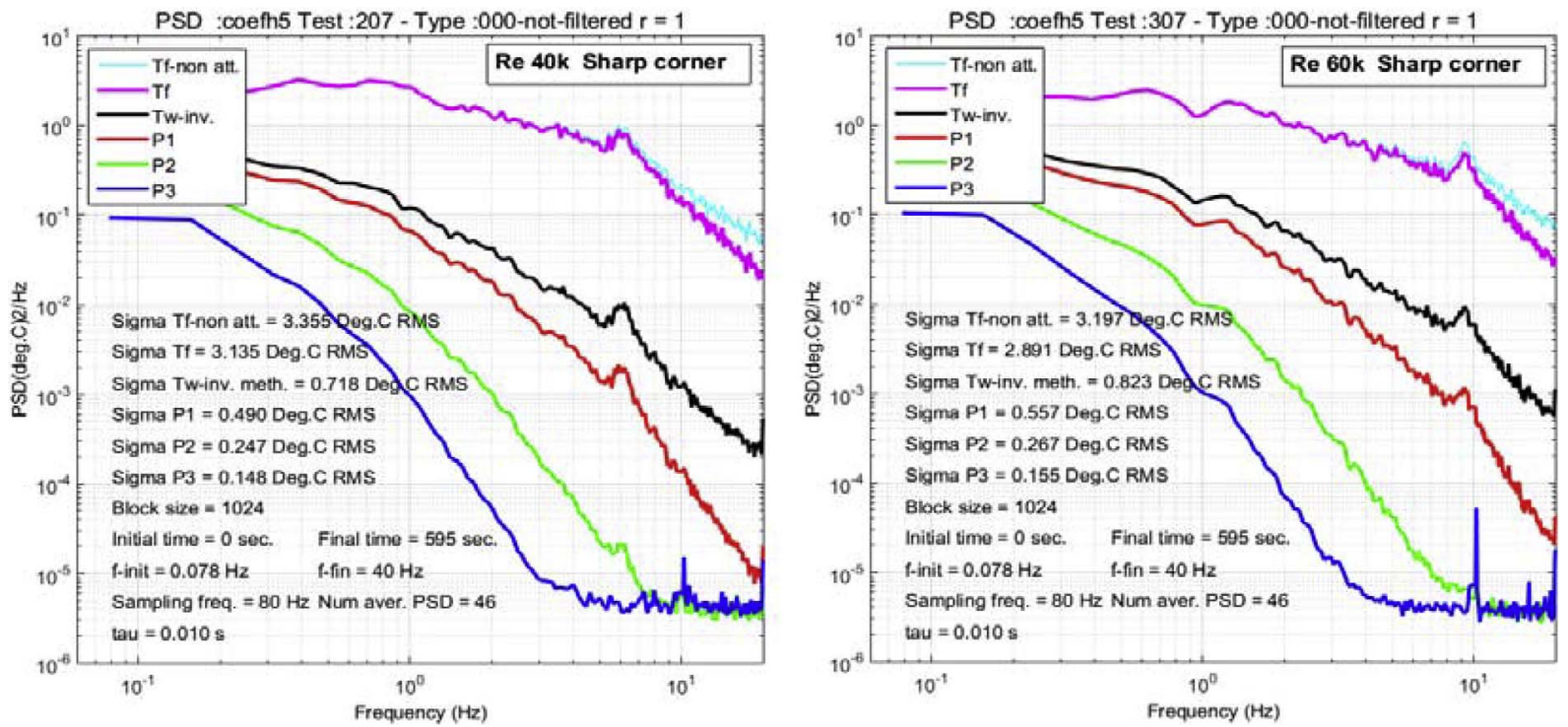

Fig. 20. Location of the thermal peak at $70^{\circ} \mathrm{X}=2.62 \mathrm{D}$ for the sharp corner configuration at $\mathrm{Re}=40000$ and $\mathrm{Re}=60000$.

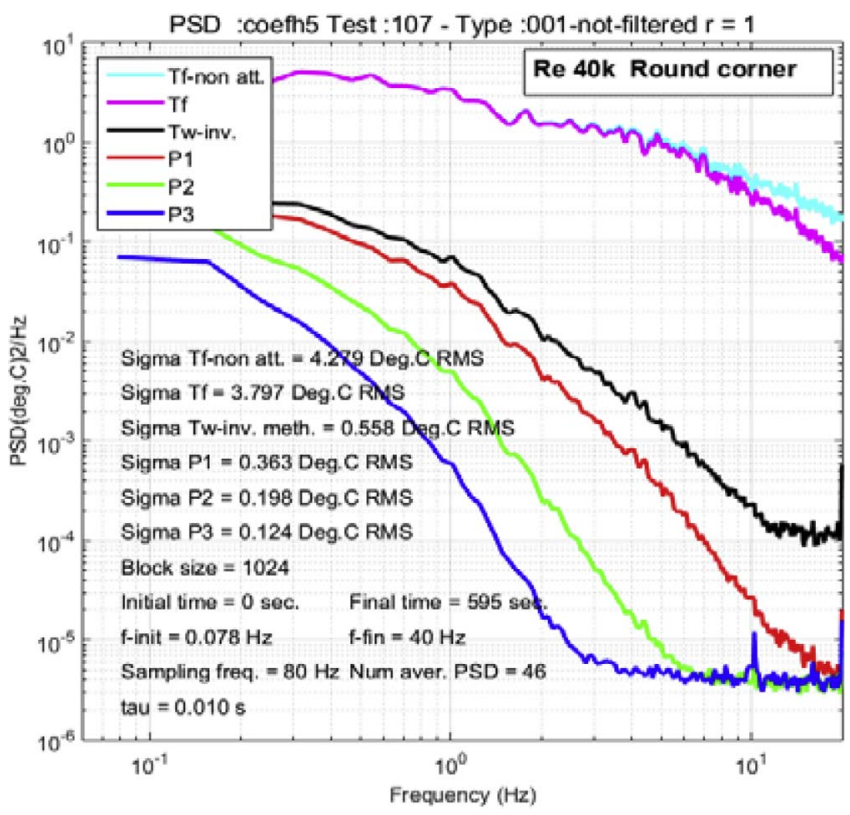

Fig. 21. PSD Tf and Tw in the fluid and in the solid at $70^{\circ} \mathrm{X}=2.62 \mathrm{D}-$ effect of the geometry (no peak for RC configuration- Re 40000). $68^{\circ} 48^{\circ} 34^{\circ} 22^{\circ} 11^{\circ} 0^{\circ}-11-22^{\circ}-34^{\circ}-48^{\circ}-68^{\circ}$

referenced on the horizontal $\mathrm{x}$ axis of the infrared frame. That corresponds to the following azimuthal angles in the 304L mock-up reference $22^{\circ} \quad 42^{\circ} \quad 56^{\circ} \quad 68^{\circ} \quad 79^{\circ} \quad 90^{\circ} \quad 101^{\circ} \quad 112^{\circ} \quad 124^{\circ} \quad 138^{\circ} \quad 158^{\circ}$

Basically, the IR sections of pixels are located to the same distance than the thermal and LDV measurements from 304L mock-ups. The distances from the z-axis of the vertical line for 100 type tests (400_100, 500_100, and 600_100) are:

- IR Section \#1: $-0.5 \mathrm{D}$

- IR Section \#2: 0

- IR Section \#3: 0.5

- IR Section \#4: $1.86 \mathrm{D}$ (corresponding to the Window \#3)

- IR Section \#5: 2.62 D (corresponding to the \#S'1 in 304L mock-up)

- IR Section \#6: 4.18 D (corresponding to the \#S3 in 304L mock-up)

In addition, two IR sections are located corresponding to the max. RMS value in the mixing zone and in the tee, respectively, i.e. IR sections $\# \mathrm{~m} 1$ and $\# \mathrm{~m} 2$. Downstream of the tee, the 200 type view (401_200, 501_200, and 601_200) supply further IR sections such as:

- IR Section \#7: 4.95 D (corresponding to the Window \#4)

- IR Section \#8: 5.8 D (corresponding to the \#S5 in 304L mock-up)

- IR Section \#9: $8 \mathrm{D}$ (corresponding to the \#S7 in 304L mock-up)

- IR Section \#10: 9.46 D (corresponding to the Window \#5) 


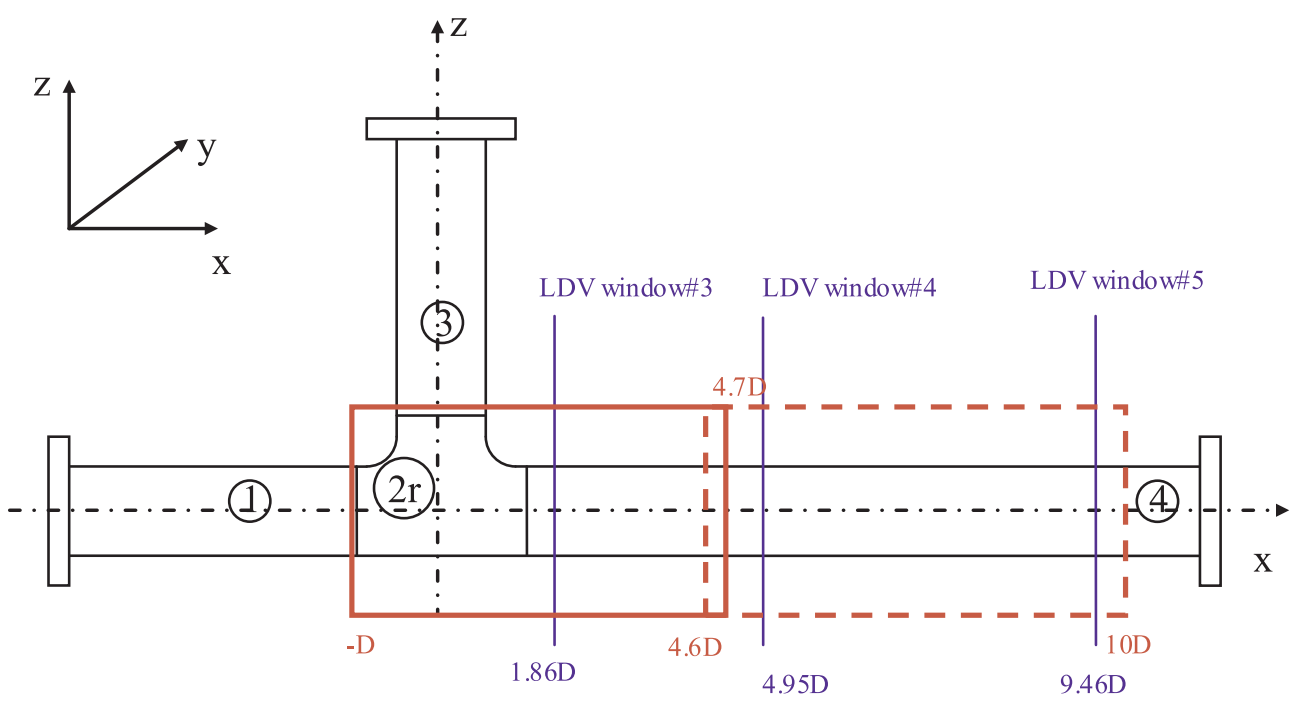

Fig. 22. Schematic figure of the infrared measurement areas.
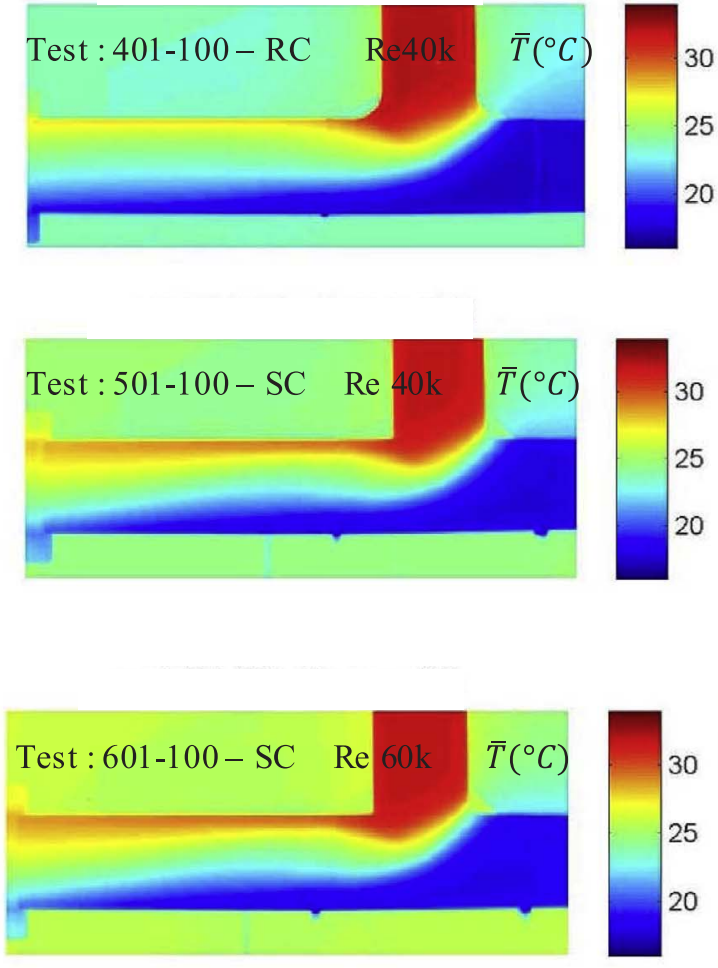
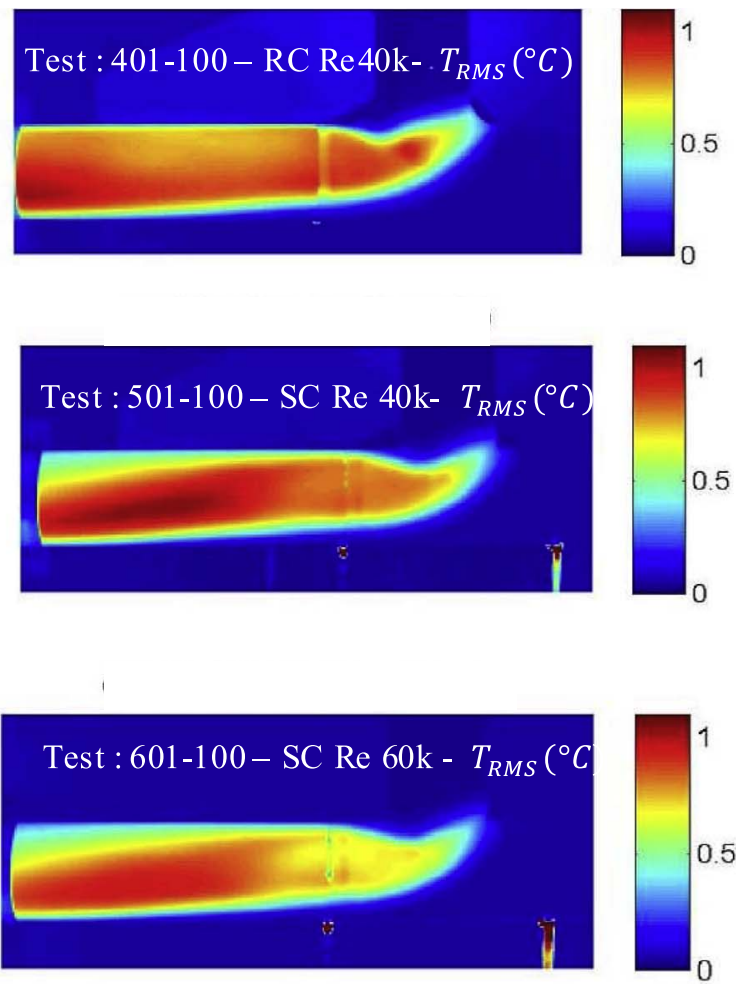

Fig. 23. Infrared temperatures (mean and RMS) for the round corner (RC) at $\mathrm{Re}=40000$ and sharp corner (SC) at $\mathrm{Re}=40000$ and 60000 .

In addition, another IR section is located corresponding to the max. RMS value in the mixing zone (IR section \#m3). The locations of the pixel sections are marked on both views of infrared frames (Figs. 24-26).

For the round corner configuration, the maximum value of $\mathrm{T}_{\mathrm{RMS}}$ is observed at 4.25 D (as shown in Fig. 24). Whereas, it is observed closer for the sharp corner configurations, at $2.92 \mathrm{D}$ and $3.36 \mathrm{D}$ for $\operatorname{Re}=40000$ and $\operatorname{Re}=60000$, respectively (Figs. 25 and 26).

As can be seen from Fig. 27, the difference between the geometric configuration are well shown on the mapping of the selected pixels of interest for the dimensionless (Dimless) RMS infrared temperature. At $2.62 \mathrm{Dh}$ and $\mathrm{Re}=40000$, the difference is very sensitive, where the max. value reaches 0.057 at $110^{\circ}$ and 0.068 at $90^{\circ}$ respectively for RC configuration and SC configuration. As shown that the max. RMS value is noted for each figure, the RMS amplitudes are similar but obtained at $2.92 \mathrm{Dh}$ and 4.25 Dh respectively for the SC and RC configuration. The amplitude of Infrared data are also similar to the dimless RMS temperature of Tw (deduced by inverse conduction) and P1 measurement (coefh05 at $2.62 \mathrm{Dh}$ ) especially if we compare data on the same treatment (see Fig. 28). Here the dimless RMS value computed within the time history signal. The profile and the max. value are almost similar moreover the location in azimuth of the max. value, only the attenuation factor 1,2 is lightly different, 0.058 and 0.049 respectively for infrared and temperature in 304L.

The dimless RMS value deduced from the PSD method (from $0.08 \mathrm{~Hz}$ to $40 \mathrm{~Hz}$ overall spectrum) which tend to minimize the low frequency shows nevertheless the same profiles (see Fig. 29).

As the conductivity is higher in the brass mock-up than in the 304L, 

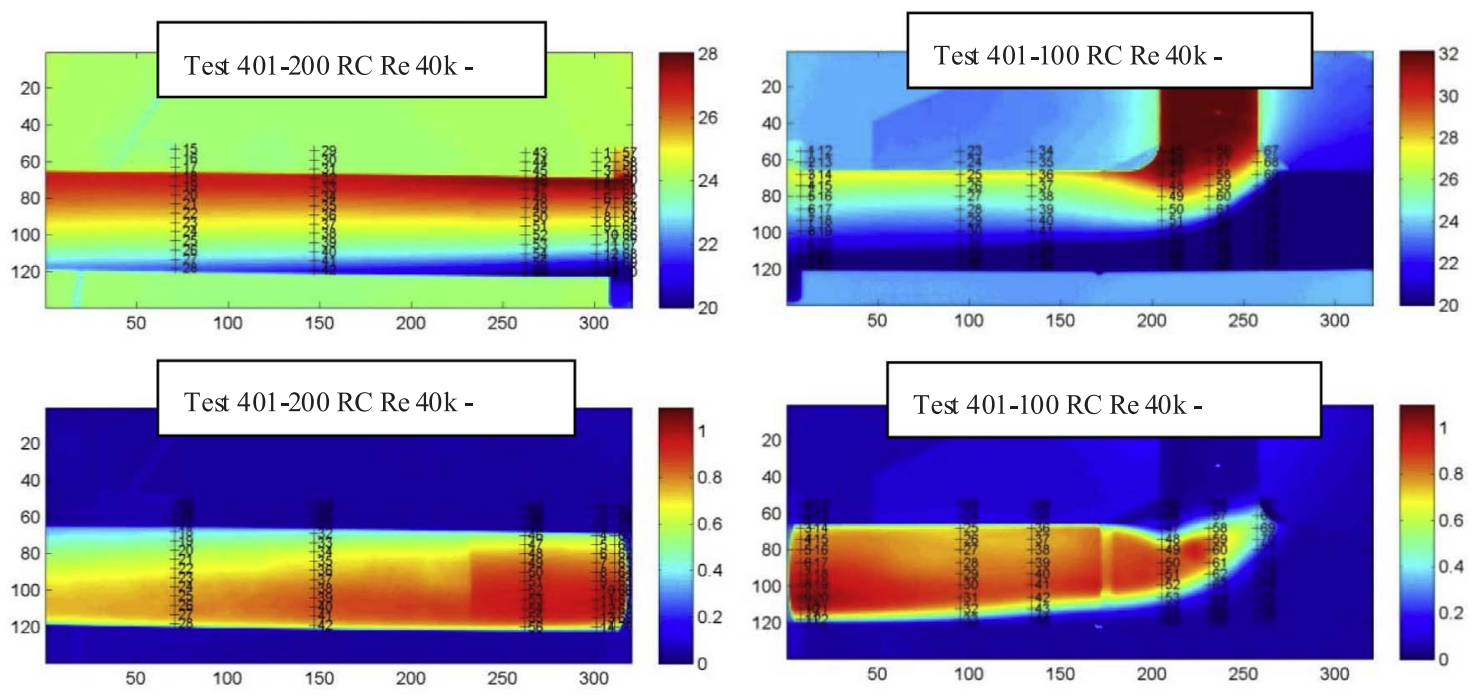

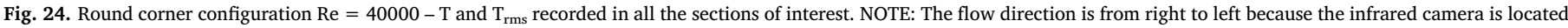
on the other side of the LDV measurements.
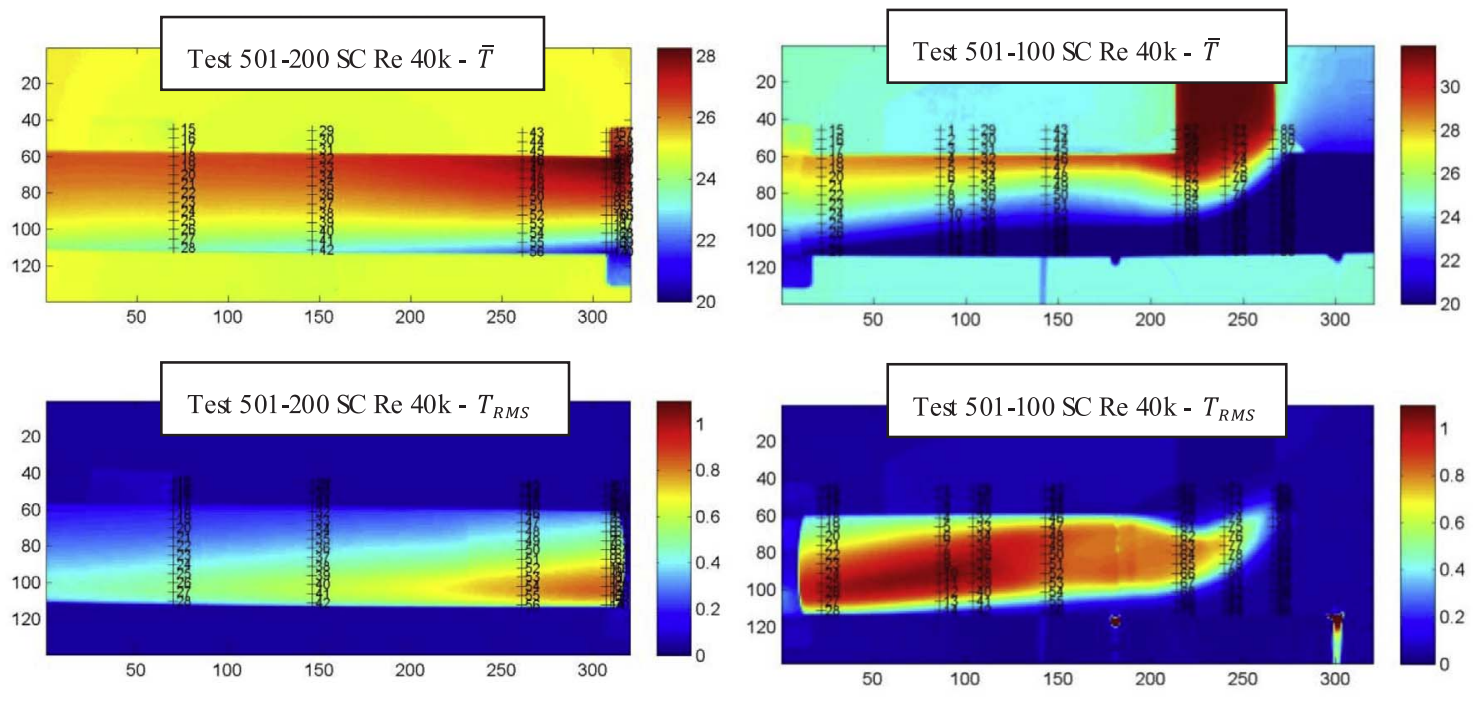

Fig. 25. Sharp corner configuration $\mathrm{Re}=40000-\mathrm{T}$ and $\mathrm{T}_{\mathrm{rms}}$ recorded in all sections of interest. NOTE: The flow direction is from right to left.
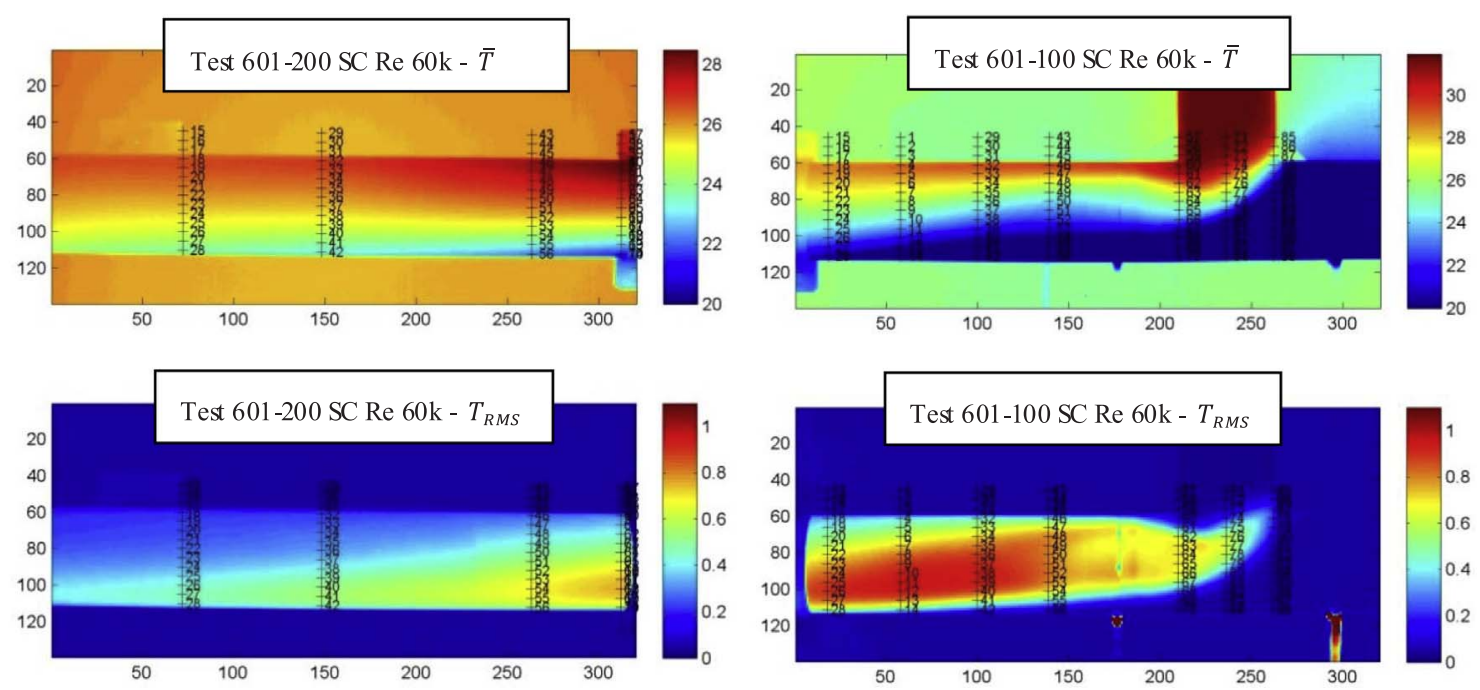

Fig. 26. Sharp corner configuration $\mathrm{Re}=60000-\mathrm{T}$ and $\mathrm{T}_{\mathrm{rms}}$ recorded in all sections of interest. NOTE: The flow direction is from right to left. 

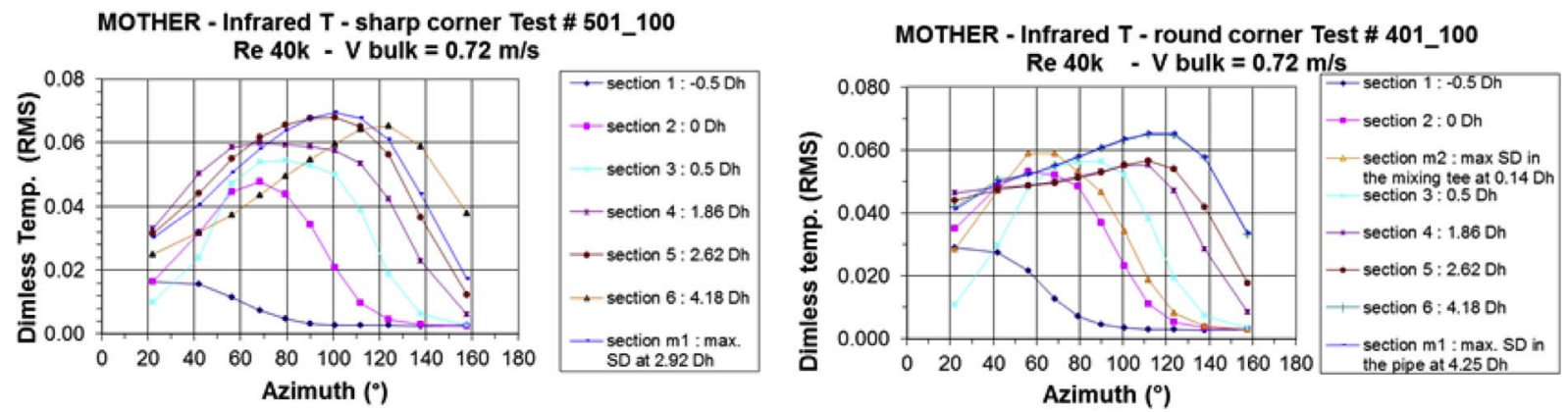

Fig. 27. Evolution of the dimensionless RMS of infrared temperature for (Left) sharp and (Right) round corner for the Re $=40000$.

Tw and P1 dimless (RMS) from overall time history signal Round Corner Re 40k - 2.62 Dh

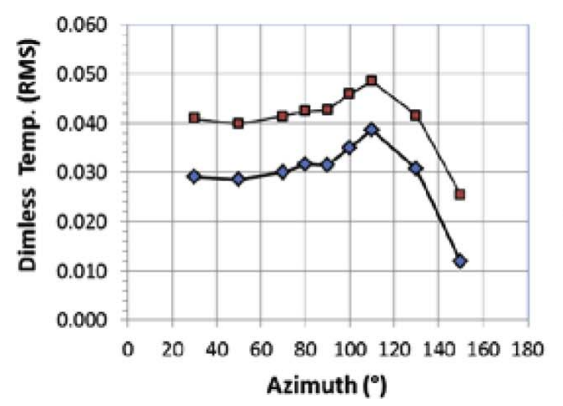

$\rightarrow-R M S T w$ Time history

$\rightarrow-$ RMS P1 Time history

Fig. 28. Evolution of the dimensionless RMS of Tw and P1 (coefh05 at $2.62 \mathrm{Dh}$ ), deduced from time history signal, for round corner $(\mathrm{Re}=40000)$.

Tw and P1 dimless (RMS) PSD from $0.08 \mathrm{~Hz}$ to $40 \mathrm{~Hz}$ Round Corner Re 40k - 2.62 Dh

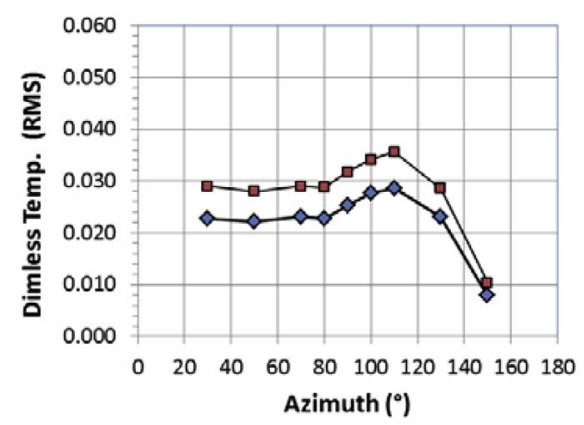

$\rightarrow$ RMS Tw PSD $(0.08$ $\mathrm{Hz}$ to $40 \mathrm{~Hz}$ )

$\rightarrow$ RMS P1 PSD $(0.08$ $\mathrm{Hz}$ to $40 \mathrm{~Hz}$ )

Fig. 29. Evolution of the dimensionless RMS of Tw and P1 (coefh05 at $2.62 \mathrm{Dh}$ ), deduced from the PSD, for round corner $(\mathrm{Re}=40000)$.

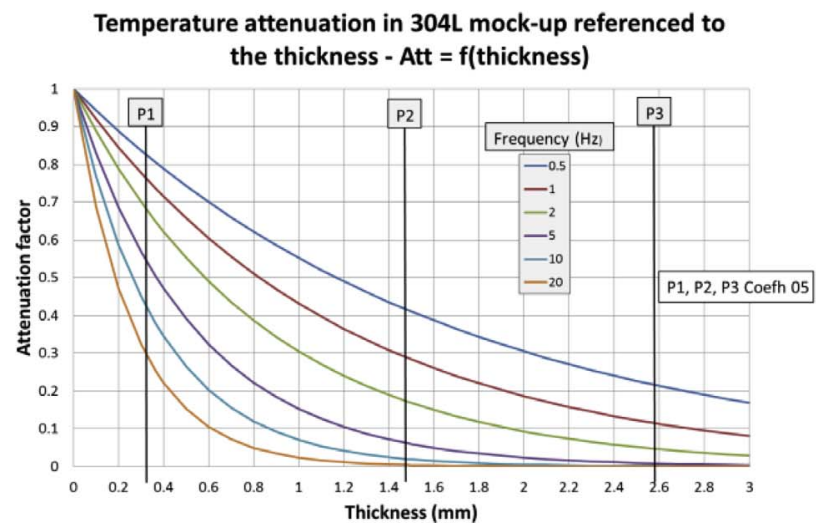

the fluctuation in the wall are less attenuated. The Biot number characterizes the property of passing the thermal fluctuation (transparency of the wall).

Biot $=\frac{h e}{\lambda}$

By assuming a $\mathrm{h}=5000 \mathrm{~W} / \mathrm{m}^{2} . \mathrm{K}$, the difference Biot number between both material is:

Biot $($ brass $)=\frac{5000 \times 0.001}{111}=0.045$

Biot $(304 L)=\frac{5000 \times 0.00953}{16.1}=2.96$

Moreover, the relation between the inner wall surface temperature for thick $304 \mathrm{~L}$ and the outer surface temperature of the thin brass is given by the law of decreasing of the fluctuation in the thickness of the wall in non-stationary situation. For the 1D model the attenuation factor (without the phase effect only the modulus) is given by:

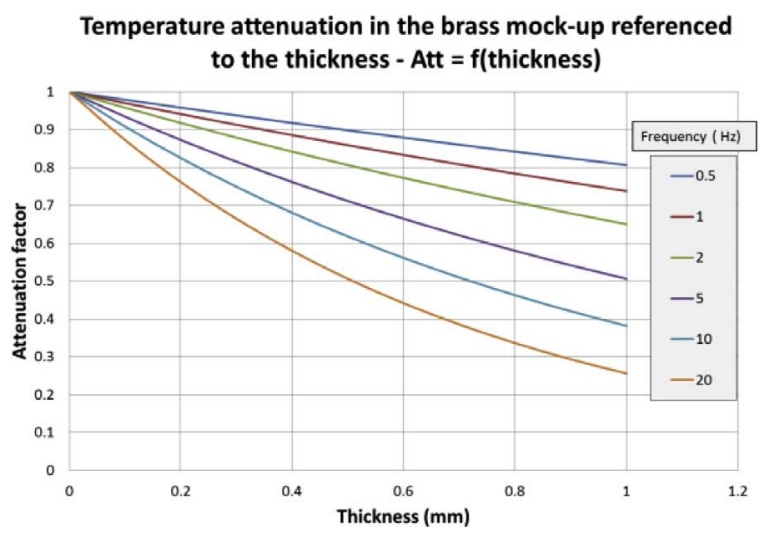

Fig. 30. Difference between the response inside the wall respectively for $304 \mathrm{~L}$ and brass mock-ups. 
$T(x, \omega)=T \cdot e^{-x \sqrt{\frac{\omega}{2 \alpha}}}$

The best comparison can be deduced from the measurement, for instance at $5 \mathrm{~Hz}$ which is a frequency of interest for the simulation. From the inner wall temperature, the infrared fluctuating temperature is attenuated by 0.506 factor and 0.505 in the 304L mock-up, for the first TC (P1-coefh05) (see Fig. 30). The RMS temperature should be similar, but it is not the case, but in spite of all physical effects, the thickness effect on the thin brass mock-up is high, for example at $0.9 \mathrm{~mm}$ the factor increases at $0.541(7 \%)$ for the brass mock-up.

\section{Conclusions}

The FATHERINO facility is specifically designed to study thermal loads of mixing in T-junction geometries. The instrumentation includes LDV (for the local velocity profile) and thermal measurements (temperature fluctuations in the solid wall and in the fluid). Equal T-junction mock-ups (54 mm internal diameter) in 304L stainless steel material are tested with two different internal geometries, a round and a sharp corner. The fluid temperature difference is $15^{\circ} \mathrm{C}$ with $15^{\circ} \mathrm{C}$ and $30^{\circ} \mathrm{C}$ respectively for the cold and hot streams. The flowrates in the two pipes are the same. Two flowrates have been tested and the Reynolds numbers are 40000 and 60000 . The results indicate that the Reynolds number does not have a large impact on the flow, however the round corner and the sharp corner are different in some aspects. The round corner does not have a separation zone which is as pronounced as in the sharp corner case and the relaxation towards a uniform velocity profile is faster. Furthermore, in the sharp corner the temperature fluctuations in the fluid and in the wall have a characteristic Strouhal number, which is not the case for the round corner case. When it comes to the amplitude of the temperature fluctuations in the solid wall, the Reynolds number has a large effect since it increases the heat transfer. The results from the MOTHER experiment provide a novel open database for the validation of CFD simulations for thermal load determination. These can be used in order to improve the thermal fatigue assessments in T-junction configurations at e.g. nuclear power plants.

\section{Acknowledgements}

NUGENIA (successor of NULIFE) is highly acknowledged for being the framework within which the MOTHER project has been initiated. The core group members EDF, EON, Areva and Vattenfall are highly acknowledged for making the project possible through financial support. All members are highly acknowledged for their in-kind contributions without which the project would have not been possible. This paper is dedicated to Lars Andersen who was an important contributor to the work.

\section{References}

Braillard, O., Berder, O., Escourbiac, F., Contans, S., 2006. An Advanced Mixing Tee Mock-up Called "The Skin of the Fluid" Designed to Qualify the Numerical LES Analysis Applied to the Thermal Evaluation: PVP2006-ICPVT-11-93662, Vancouver, Canada. .

Chapuliot, S., Gourdin, C., Payen, T., Magnaud, J.P., Monavon, A., 2005. Hydrothermalmechanical analysis of thermal fatigue in a mixing tee. Nucl. Eng. Des. 235, 575-596.

Coste, P., Quemere, P., Roubin, P., Tanaka, M., Kamide, H., 2008. Large eddy simulation of highly fluctuational temperature and velocity fields observed in a mixing-tee experiment. Nucl. Technol. 164, 76-88.

Fontes, J.P., Braillard, O., Cartier, O., Dupraz, S., 2009. Evaluation of an unsteady heat transfer coefficient in a mixing area: the FATHER experiment associated to the specific "coefh" sensor. The 13th International Topical Meeting on Nuclear Reactor Thermal Hydraulics (NURETH-13), Japan.

Gillis, J.C., Belley, B.P., Romero, M., 2013. A CFX simulation of the OECD/NEA Tjunction benchmark. Proceedings of the ASME 2013 Pressure Vessels and Piping Conference, PVP2013-97292.

Howard, R.J.A., Pasutto, T., 2009. The effect of adiabatic and conducting wall boundary conditions on LES of a thermal mixing tee. The 13th International Topical Meeting on Nuclear Reactor Thermal Hydraulics (NURETH-13), N13P1110.

Jayaraju, S.T., Komen, E.M.J., Baglietto, E., 2010. Suitability of wall-functions in Large Eddy Simulation for thermal fatigue in a T-junction. Nucl. Eng. Des. 240, 2544-2554.

Kamide, H., Igarashi, M., Kawashima, S., Kimura, N., Hayashi, K., 2009. Study on mixing behavior in a tee piping and numerical analyses for evaluation of thermal striping. Nucl. Eng. Des. 239, 58-67.

Kuhn, S., Braillard, O., Niceno, B., Prasser, H.-M., 2010. Computational study of conjugate heat transfer in T-junctions. Nucl. Eng. Des. 240 (6), 1548-1557.

Nakamura, A., Oumaya, T., Takenaka, N., 2009. Numerical investigation of thermal striping at a mixing tee using detached eddy simulation. The 13th International Topical Meeting on Nuclear Reactor Thermal Hydraulics (NURETH-13). N13P1074. Smith, B.L., Mahaffy, J.H., Angele, K., 2013. A CFD benchmarking exercise based on flow mixing in a T-junction. Nucl. Eng. Des. 264, 80-88.

Westin, J., Mannetje, C., Alavyoon, F., Veber, P., Andersson, L., Andersson, U., Eriksson, J., Henriksson, M., Andersson, C., 2008. High-cycle thermal fatigue in mixing tees. Large eddy simulations compared to a new validation experiment: ICONE16. . 